\title{
Microbial Metabolites of Flavan-3-Ols and Their Biological Activity
}

\author{
Estefanía Márquez Campos ${ }^{1,2}$, Peter Stehle ${ }^{2}$ and Marie-Christine Simon ${ }^{1, *(1)}$ \\ 1 Department of Nutrition and Food Sciences, Nutrition and Microbiota, University of Bonn, 53115 Bonn, \\ Germany; estefania.marquezc@gmail.com \\ 2 Department of Nutrition and Food Sciences, Nutritional Physiology, University of Bonn, 53115 Bonn, \\ Germany; p.stehle@uni-bonn.de \\ * Correspondence: marie-christine.simon@uni-bonn.de; Tel.: +49-228-73-36-80
}

Received: 14 August 2019; Accepted: 17 September 2019; Published: 20 September 2019

\begin{abstract}
Flavan-3-ols are the main contributors to polyphenol intake. Many varying beneficial health effects in humans have been attributed to them, including the prevention of cardiovascular disease and cancer. Nevertheless, the mechanisms by which these flavonoids could exert beneficial functions are not entirely known. Several in vitro studies and in vivo animal models have tried to elucidate the role of the specific colonic metabolites on the health properties that are attributed to the parent compounds since a larger number of ingested flavan-3-ols reach the colon and undergo there microbial metabolism. Many new studies about this topic have been performed over the last few years and, to the best of our knowledge, no scientific literature review regarding the bioactivity of all identified microbial metabolites of flavan-3-ols has been recently published. Therefore, the aim of this review is to present the current status of knowledge on the potential health benefits of flavan-3-ol microbial metabolites in humans while using the latest evidence on their biological activity.
\end{abstract}

Keywords: polyphenols; flavonoids; microbiota; metabolism

\section{Introduction}

Polyphenols exert numerous beneficial health effects in the human organism. The main contributors to polyphenol intake are flavan-3-ols [1,2], which constitute the most complex flavonoid subclass. After ingestion, flavan-3-ols can reach the colon in high proportions, where they can be transformed into microbial metabolites by the resident microbiota. These catabolites might be responsible for the health promoting effects that are attributed to the parent compounds (Figure 1). 


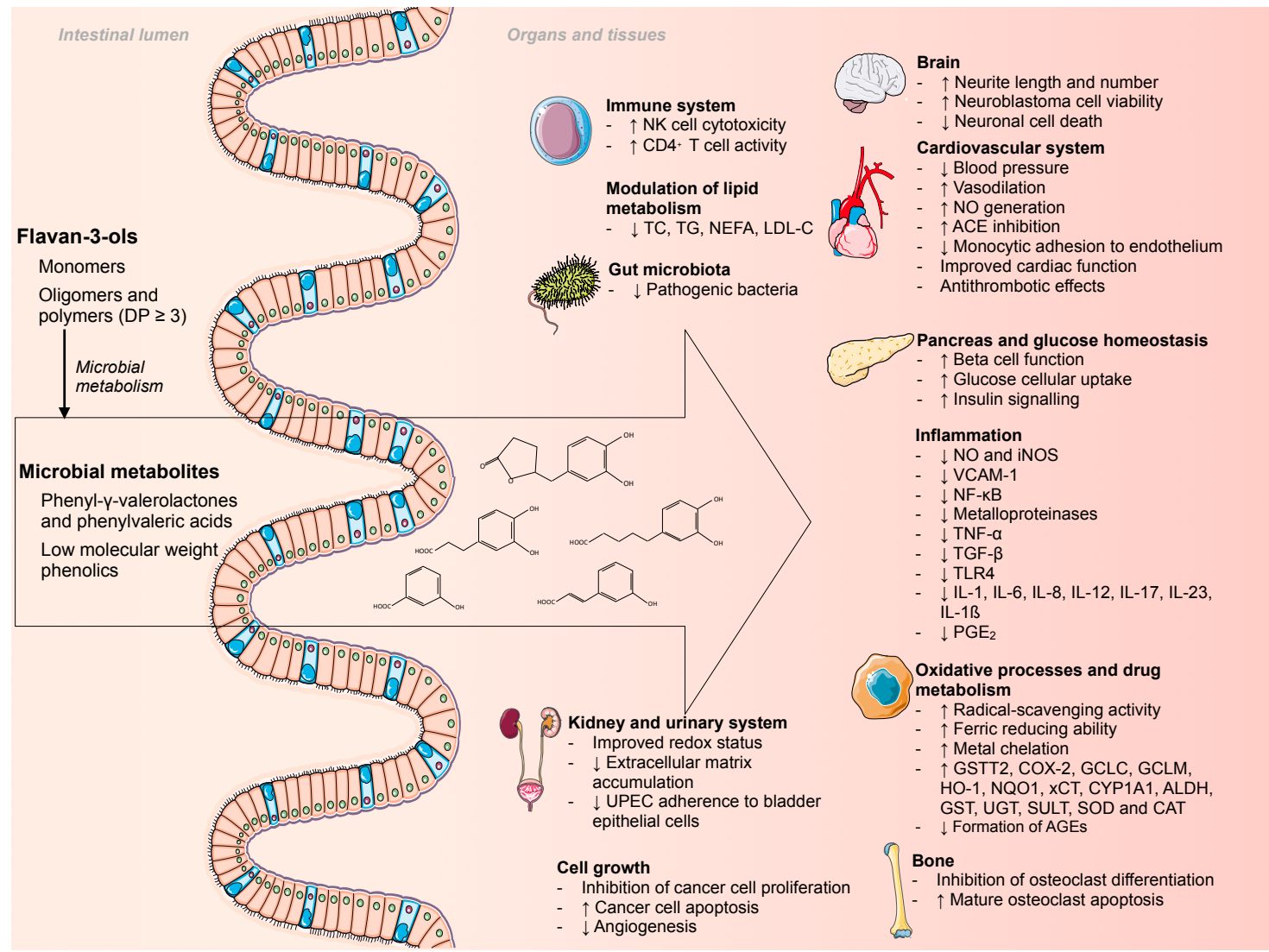

Figure 1. Schematic view of the postulated bioactivity of flavan-3-ol microbial metabolites. ACE: angiotensin I-converting enzyme; AGE: advanced glycation end-products; ALDH: aldehyde dehydrogenase; CAT: catalase; $\mathrm{CD}^{+}$cells: $\mathrm{T}$ helper cells; COX-2: cyclooxygenase-2; CYP1A1: cytochrome P450 1A1; DP: degree of polymerization; GCLC: glutamate-cysteine ligase catalytic subunit; GCLM: glutamate-cysteine ligase modifier subunit; GST: glutathione S-transferase; GSTT2: glutathione S-transferase theta-2; HO-1: heme oxygenase 1; IL: interleukin; iNOS: inducible nitric oxide synthase; LDL-C: low-density lipoprotein cholesterol; NEFA: non-esterified fatty acids; NF- $\mathrm{BB}$ : nuclear factor kappa-light-chain-enhancer of activated B cells; NK cell: natural killer cells; NO: nitric oxide; NQO1: NADH:quinone oxidoreductase-1; $\mathrm{PGE}_{2}$ : prostaglandin $\mathrm{E}_{2}$; SOD: superoxide dismutase; SULT: sulfotransferase; TC: total cholesterol; TG: triglycerides; TLR-4: toll-like receptor 4; TNF: tumor necrosis factor; UGT: UDP-glucuronosyltransferase; UPEC: uropathogenic Escherichia coli; VCAM: vascular cell adhesion molecule; xCT: cystine/glutamate anti-porter.

Monagas et al. laboriously complied all of the available scientific information related to the metabolic pathway of flavan-3-ols in the human organism and reviewed the biological activities that were attributed to their phase-II and microbial metabolites [3]. However, since then, many new studies regarding this topic have been performed and, to the best of our knowledge, no other scientific literature review about the bioactivity of all of the identified microbial metabolites of flavan-3-ols to date has been recently published. Only Mena et al. recently addressed the bioactivity of phenyl- $\gamma$-valerolactones and phenylvaleric acids: two of the several groups of flavan-3-ol colonic metabolites [4]. Thus, the aim of this review is to summarize the most recent scientific publications on biological activity of microbial metabolites of flavan-3-ols to present the current status of knowledge on this topic.

\section{Origin}

Flavan-3-ols are present in food not only in the form of monomers, but also as oligomeric and polymeric proanthocyanidins, whose degree of polymerization can reach up to 50 units or more [5]. 
They are commonly found in foods, such as fruits, green tea, red wine, and chocolate [6], although the main dietary source in the population differs demographically and, therefore, the type of flavan-3-ol that is consumed also differs [7]. Their original content in food can also vary due to several factors, such as the plant variety, the time of harvest, environmental factors, processing, and storage conditions [6]. For this reason, flavan-3-ol content in foods has been detected at very different concentrations ranging, for example, between 6 and $544 \mathrm{mg} / 100 \mathrm{~g}$ green tea, or between 77 and $273 \mathrm{mg} / 100 \mathrm{~g}$ dark chocolate [7].

These flavonoids have been shown to exert beneficial health effects in humans in observational as well as in intervention studies. For example, their intake might prevent cardiovascular diseases [8] or cancer [9]. Nevertheless, the mechanisms by which they could have this positive impact on health are not entirely known. In fact, the bioavailability of flavan-3-ols might be lower than $4 \%$ in humans [10].

Several factors could have an influence on bioavailability, such as food matrix, compound concentration, or gut microbiota composition. Additionally, the degree of polymerization influences their bioavailability: generally, monomeric flavan-3-ols can be absorbed in the small intestine, while the structures with a higher polymerization degree are metabolized by the intestinal microbiota before they are finally absorbed [3].

Therefore, the fact that a large proportion of flavan-3-ols reach the colon suggests that they might not be the active substances that exert beneficial physiological effects.

\section{Biological Properties of Flavan-3-O1 Microbial Metabolites}

After the unabsorbed flavan-3-ols reach the colon, free monomeric forms are released and then become available for microbial transformation (Figure 1). These free monomers are converted by specific bacteria into diphenylpropan-2-ols before being further transformed to phenyl- $\gamma$-valerolactones, which are intermediate metabolites that are exclusive to flavan-3-ols (Figure 2). Further reactions, which include breaking the valerolactone ring and dihydroxylation, form various forms of phenylvaleric acids $[3,4]$.

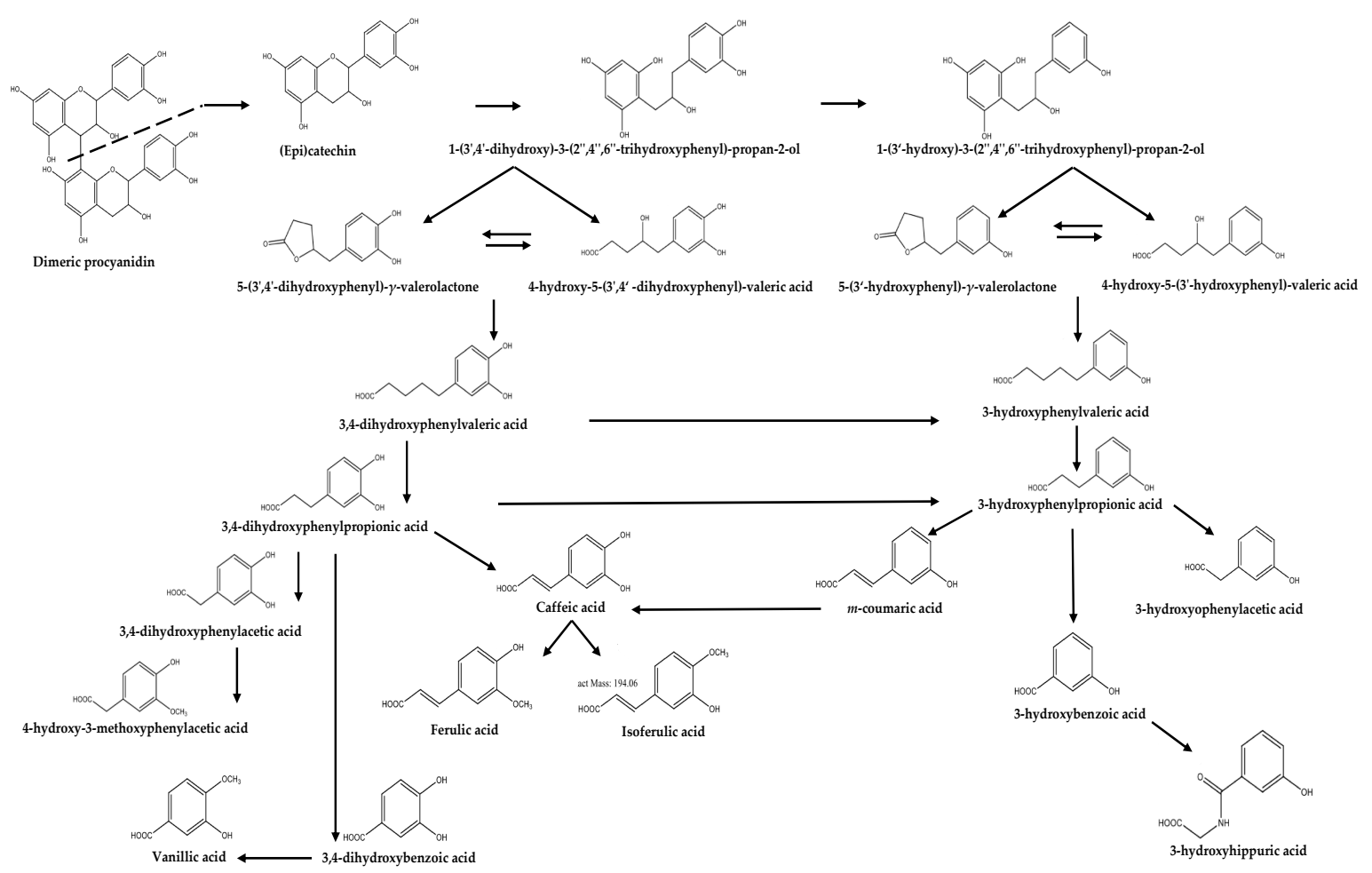

Figure 2. Metabolic pathway of flavan-3-ols in the colon.

The further bacterial metabolism of phenyl- $\gamma$-valerolactones and phenylvaleric acids produces different hydroxylated forms of phenyl and benzoic acids by the loss of carbon atoms from the side 
chain through B-oxidation (Figure 2) [3]. The 3,4-dihydroxylated phenolic acids are dehydroxylated at C-4' and C-3', producing 3- and 4-monohydroxylated phenolic acids [3]. Metabolites, like vanillic acid, homovanillic acid, hippuric acid, or $p$-coumaric acid, have also been related to the intestinal catabolism of flavan-3-ols (Figure 2) [3]. These low molecular weight phenolic acids are, in contrast to phenyl- $\gamma$-valerolactones, not specific to flavan-3-ols, since they can also be formed after the metabolism of other flavonoids [11,12].

After absorption, colonic metabolites undergo phase II metabolism in the liver and their conjugated derivatives reach the organs and tissues, where they will exert their beneficial effects. They can also be eliminated in the urine and faeces [3].

Unlike the native monomeric and, especially, the oligomeric and polymeric flavan-3-ols, colonic metabolites are highly bioavailable in the human organism. In fact, their absorption has been shown to occur at a much higher rate than in the case of the parent compounds [10,13-15]. Phenyl- $\gamma$-valerolactones and phenylvaleric acids have been previously found at concentrations lower than $1 \mu \mathrm{M}$ in plasma [15-19]. The smaller phenolics have been mainly found at concentrations lower than $0.5 \mu \mathrm{mol} / \mathrm{L}$ [16-19], but in some cases, such as phenylacetic acid, protocatechuic acid, and hippuric acid, the concentrations could reach $\approx 40 \mu \mathrm{mol} / \mathrm{L}[16,20]$.

\subsection{Phenyl- $\gamma$-valerolactones and Phenylvaleric Acids}

Table 1 presents an overview of the studies that were performed over the last few years regarding the biological activities, and including the physiological importance, of phenyl- $\gamma$-valerolactones and phenylvaleric acids that, according to the available literature, are related to the human colonic metabolism of monomeric flavan-3-ols and proanthocyanidins [3,5].

Table 1. Biological activity of phenyl- $\gamma$-valerolactones and phenylvaleric acids. ${ }^{1}$

\begin{tabular}{|c|c|c|c|c|}
\hline Test/Model & Microbial Metabolite & $\begin{array}{l}\text { Concentration/ } \\
\text { Dose }\end{array}$ & Results & Ref. \\
\hline \multicolumn{5}{|c|}{ Anti-adhesive activity } \\
\hline $\begin{array}{l}\text { NO formation and } \\
\text { iNOS expression in } \\
\text { LPS-exposed RAW } \\
\text { 264.7 macrophage; } \\
\text { binding to RAW } \\
\text { 264.7, EA.hy } 926 \\
\text { endothelial cell and } \\
\text { human monocyte }\end{array}$ & 5-(3', 4'-dihydroxyphenyl)- $\gamma$-VL & $\begin{array}{c}\mathrm{IC}_{50}=1.3-3.8 \\
\mu \mathrm{g} / \mathrm{mL}\end{array}$ & $\begin{array}{c}\text { NO production and iNOS expression were } \\
\text { inhibited in a concentration-dependent } \\
\text { manner. High binding capacity to RAW } \\
\text { 264.7, EA.hy } 926 \text { and human monocytes, } \\
\text { which was reduced in the presence of } \\
\text { phloretin. }\end{array}$ & [22] \\
\hline $\begin{array}{l}\text { Systolic blood } \\
\text { pressure in } \\
\text { spontaneously } \\
\text { hypertensive rats and } \\
\text { ACE activity }\end{array}$ & $\begin{array}{c}\text { 5-(3,4,5-trihydroxyphenyl)- } \gamma \text {-VL; } \\
\text { 5-(3,5-dihydroxyphenyl)- } \gamma \text {-VL; } \\
\text { 4-hydroxy-5-(3,4,5-trihydroxyphenyl)ValA; } \\
\text { 4-hydroxy-5-(3,5-dihydroxyphenyl)-ValA; } \\
\text { 5-(3,4,5-trihydroxyphenyl)ValA; } \\
\text { 5-(3,5-dihydroxyphenyl)ValA; } \\
\text { 5-(3-hydroxyphenyl)ValA }\end{array}$ & $\begin{array}{l}150-200 \mathrm{mg} / \mathrm{kg} \\
\mathrm{IC}_{50}= \\
1.51-19.59 \mu \mathrm{M}\end{array}$ & $\begin{array}{c}\text { Systolic blood pressure decreased } 2 \mathrm{~h} \text { after } \\
150 \mathrm{mg} / \mathrm{kg} \text { 5-(3,4,5-trihydroxyphenyl)- } \gamma \text {-VL } \\
\text { intake, and } 4 \mathrm{~h} \text { after } 200 \mathrm{mg} / \mathrm{kg} \\
\text { 5-(3,5-dihydroxyphenyl)- } \gamma \text {-VL. The order of } \\
\text { ACE inhibitory activity was: EGCG > } \\
\text { 5-(3,4,5-trihydroxyphenyl)ValA > } \\
\text { 5-(3,5-dihydroxyphenyl)ValA > } \\
\text { 5-(3,4,5-trihydroxyphenyl)- } \gamma \text {-VL } \cong \\
\text { 5-(3-hydroxyphenyl)ValA > EC > } \\
\text { 4-hydroxy-5-(3,4,5-trihydroxyphenyl)ValA } \\
>>\text { 4-hydroxy-5-(3,5-dihydroxyphenyl)-ValA } \\
\text { >> 5-(3,5-dihydroxyphenyl)- } \gamma \text {-VL. }\end{array}$ & [23] \\
\hline $\begin{array}{l}\text { THP-1 monocyte } \\
\text { adhesion to } \\
\text { TNF- } \alpha \text {-stimulated } \\
\text { human umbilical } \\
\text { vein endothelial cells }\end{array}$ & 5-(3', 4'-dihydroxyphenyl)- $\gamma$-VL & $7.5-30 \mu \mathrm{M}$ & 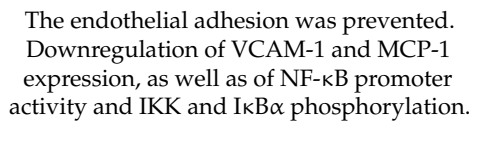 & [24] \\
\hline
\end{tabular}


Table 1. Cont.

\begin{tabular}{|c|c|c|c|c|}
\hline Test/Model & Microbial Metabolite & $\begin{array}{c}\text { Concentration/ } \\
\text { Dose }\end{array}$ & Results & Ref. \\
\hline \multicolumn{5}{|c|}{ Chemopreventive effect } \\
\hline $\begin{array}{c}\text { Proliferation of } \\
\text { human cervical } \\
\text { cancer cell (HeLa) }\end{array}$ & $\begin{array}{c}\text { 4-hydroxy-5-(3,5-dihydroxyphenyl)VA; } \\
\text { 5-(3,5-dihydroxyphenyl)- } \gamma \text {-VL; } \\
\text { 4-hydroxy-5-(3,4,5- trihydroxyphenyl)ValA; } \\
\text { 5-(3,4,5-tri-hydroxyphenyl)- } \gamma \text {-VL; } \\
\text { 5-(3,4,5-trihydroxy-phenyl)ValA; } \\
\text { 5-(3,5-dihydroxyphenyl)ValA; } \\
\text { 5-(3-hydroxyphenyl)ValA; } \\
\text { 4-hydroxy-5-(3,4-dihydroxyphenyl)ValA; } \\
\text { 5-(3,4-dihydroxyphenyl)ValA }\end{array}$ & $50 \mu \mathrm{g} / \mathrm{mL}$ & $\begin{array}{c}\text { 4-hydroxy-5-(3,4,5-trihydroxyphenyl)ValA, } \\
\text { 5-(3,4,5-trihydroxyphenyl)ValA and } \\
\text { 5-(3,4-dihydroxyphenyl)ValA inhibited the } \\
\text { proliferation of HeLa cells by } 71.9 \%, 13.5 \% \\
\text { and } 53.9 \% \text {, respectively (relative to negative } \\
\text { control set at 100, DMSO). } \\
\text { 5-(3,4,5-trihydroxyphenyl)ValA had the } \\
\text { strongest inhibitory activity among the } \\
\text { metabolites }\left(\mathrm{IC}_{50}=5.58 \mu \mathrm{M}\right) \text {. }\end{array}$ & [25] \\
\hline $\begin{array}{l}\text { Proliferation of } \\
\text { androgen-dependent } \\
\text { human prostate } \\
\text { cancer cells (LNCaP) }\end{array}$ & 5-(3',4',5'-trihydroxyphenyl)- $\gamma$-VL & $\mathrm{IC}_{50}=117 \mu \mathrm{M}$ & $\begin{array}{l}\text { Inhibition of LNCaP proliferation. } \\
\text { DHT-induced nuclear translocation of AR } \\
\text { was inhibited in } 54.5 \pm 4.7 \% \text { of cells. }\end{array}$ & [26] \\
\hline \multicolumn{5}{|c|}{ Immunomodulatory activity } \\
\hline $\begin{array}{l}\text { NK cell cytotoxicity } \\
\text { against murine } \\
\text { lymphoma YAC-1 } \\
\text { target cells in mouse } \\
\text { splenocytes treated } \\
\text { in vivo; activation of } \\
\text { mice splenic CD4 } 4^{+} \mathrm{T} \\
\text { cells }\end{array}$ & 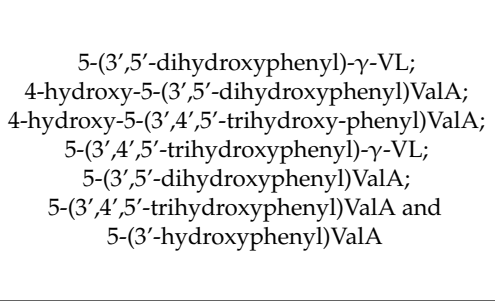 & $\begin{array}{c}10 \mathrm{mg} / \mathrm{kg} \\
10 \mu \mathrm{M}\end{array}$ & $\begin{array}{l}\text { NK cell cytotoxic activity increased in the } \\
5 \text {-( } 3^{\prime}, 5^{\prime} \text {-dihydroxyphenyl)- } \gamma \text {-VL intake } \\
\text { group. IFN- } \gamma \text { production was also } \\
\text { dose-dependently increased. } \\
\text { The order of CD4 }{ }^{+} \text {T cell activity (ATP) was: } \\
5-\left(3^{\prime} \text {-hydroxyphenyl)ValA > }\right. \\
\text { 4-hydroxy-5-( } 3^{\prime}, 5^{\prime} \text {-dihydroxyphenyl)ValA = } \\
5-\left(3^{\prime}, 5^{\prime} \text {-dihydroxyphenyl)- } \gamma \text {-VL }>\right. \\
5-\left(3^{\prime}, 5^{\prime} \text {-dihydroxyphenyl)ValA }>\right. \\
4^{\prime} \text {-dehydroxylated EGC. }\end{array}$ & [27] \\
\hline \multicolumn{5}{|c|}{ Neuroprotective effect } \\
\hline $\begin{array}{l}\text { Human SH-SY5Y } \\
\text { neuroblastoma cells } \\
\text { growth and neurite } \\
\text { outgrowth }\end{array}$ & $\begin{array}{c}5-\left(3^{\prime}, 5^{\prime} \text {-dihydroxyphenyl)- } \gamma \text {-VL and its }\right. \\
\text { conjugated forms (glucuronide and sulfate } \\
\text { forms) }\end{array}$ & $0.05 \mu \mathrm{M}$ & $\begin{array}{l}\text { 5-( } 3^{\prime}, 5^{\prime} \text {-dihydroxyphenyl)- } \gamma \text {-VL enhanced } \\
\text { SH-SY5Y cell number. Neurite length and } \\
\text { number was significantly increased by } \\
5-\left(3^{\prime}, 5^{\prime} \text {-dihydroxyphenyl)- } \gamma \text {-VL and its }\right. \\
\text { sulfated form. Glucuronide only increased } \\
\text { neurite number. }\end{array}$ & [28] \\
\hline
\end{tabular}

${ }^{1}$ ACE: angiotensin I-converting enzyme; $\mathrm{CD}^{+}$cells: T helper cells; DHT: dihydrotestosterone; DMSO: dimethyl sulfoxide; IFN $\gamma$ : interferon gamma; IKB $\alpha$ : NF- $\mathrm{kB}$ inhibitor $\alpha$; IC $_{50}$ : half maximal inhibitory concentration; IKK: IкB kinase; iNOS: inducible nitric oxide synthase; LPS: lipopolysaccharide; MCP-1: monocyte chemoattractant protein 1; NF-кB: nuclear factor kappa-light-chain-enhancer of activated B cells; NK cells: natural killer cells; NO: nitric oxide; TNF- $\alpha$ : tumor necrosis factor; VCAM: vascular cell adhesion molecule; Flavan-3-ols and microbial metabolites. EGC: (-)-epigallocatechin; ValA: valeric acid; VL: valerolactone.

\subsubsection{Anti-adhesive Activity}

Urinary tract infections are often caused by Escherichia coli [29] and cranberry has been commonly used for its treatment, because proanthocyanidins are believed to prevent bacterial adhesion to uroepithelial cells $[30,31]$. However, since these complex structures are rarely found in high amounts in plasma or urine after ingestion, Mena et al. investigated the anti-adhesive effect of one of its metabolites, 5-(3',4'-dihydroxyphenyl)- $\gamma$-valerolactone, and its conjugated forms [21]. At a concentration of $100 \mu \mathrm{M}$, the metabolites significantly inhibited the adherence of uropathogenic E. coli to T24 bladder epithelial cells [21]. The most effective derivative at this concentration was 5-phenyl- $\gamma$-valerolactone- $3^{\prime}, 4^{\prime}$-di-O-sulphate, which led to a $30.3 \pm 3.6 \%$ inhibition of adherence. The unconjugated form exerted the lowest inhibitory effect, with $19.4 \pm 10.3 \%$ adherence inhibition [21]. At $50 \mu \mathrm{M}$, only 5-(3'-hydroxyphenyl)- $\gamma$-valerolactone-4'-O-sulphate significantly inhibited the adhesion [21].

\subsubsection{Anti-inflammatory Activity}

Uhlenhut et al. studied the effect of 5-( $3^{\prime}, 4^{\prime}$-dihydroxyphenyl)- $\gamma$-valerolactone on nitric oxide (NO) production and inducible nitric oxide synthase (iNOS) expression by RAW 264.7 murine macrophages after lipopolysaccharide (LPS) stimulation [22]. NO production and iNOS expression were both inhibited by the microbial metabolite in a concentration-dependent manner ( $\mathrm{IC}_{50}=1.3 \mu \mathrm{g} / \mathrm{mL}$, $\mathrm{IC}_{50}=3.8 \mu \mathrm{g} / \mathrm{mL}$, respectively) [22]. Interestingly, the authors also found that the metabolite had high binding capacity to macrophages, endothelial cells, and monocytes [22]. 


\subsubsection{Cardiovascular Protective Effect}

Phenyl- $\gamma$-valerolactones and phenylvaleric acids could contribute to the preventive effects that were attributed to flavan-3-ols on cardiovascular diseases through hypotensive properties and by attenuating the monocyte adhesion to endothelial cells that are involved in the development of atherosclerosis.

Particularly, two metabolites of (-)-epigallocatechin gallate produced by intestinal microbiota, namely 5-(3,4,5-trihydroxyphenyl)- $\gamma$-valerolactone and 5-(3,5-dihydroxyphenyl)- $\gamma$-valerolactone, were reported to have hypotensive effects in vivo in rats [23]. The first metabolite that was administered at a concentration of $150 \mathrm{mg} / \mathrm{kg}$ significantly decreased systolic blood pressure $2 \mathrm{~h}$ after intake when compared to the control group [23]. In contrast, the second metabolite required a higher oral dosage of $200 \mathrm{mg} / \mathrm{kg}$ to exert an effect on systolic blood pressure $4 \mathrm{~h}$ after its administration [23]. Moreover, hydroxyphenyl valeric acids that were also derived from (-)-epigallocatechin gallate metabolism (5-(3,4,5-trihydroxyphenyl)valeric acid, 5-(3,5-dihydroxyphenyl)valeric acid and 5-(3-hydroxyphenyl)valeric acid) showed strong inhibitory activity of angiotensin I-converting enzyme (ACE) with an $\mathrm{IC}_{50}$ higher than that of (-)-epicatechin, but lower than (-)-epigallocatechin gallate [23].

Recently, Lee et al. reported that monocyte-endothelial cell adhesion was dose-dependently prevented after treatment with 5-(3',4'-dihydroxyphenyl)- $\gamma$-valerolactone at concentrations under $30 \mu \mathrm{M}$ [24]. Two of the main molecules that were involved in the monocyte-endothelial adhesion are vascular cell adhesion molecule (VCAM)-1 and monocyte chemoattractant protein (MCP)-1, and their tumor necrosis factor (TNF- $\alpha$ )-stimulated expression was downregulated after treatments with the phenyl- $\gamma$-valerolactone at concentrations between 7.5 and $30 \mu \mathrm{M}$ [24]. This was possibly due to the parallel downregulation of the phosphorylation of two nuclear factor kappa $\mathrm{B}(\mathrm{NF}-\mathrm{kB})$ activation signalling regulators as well as NF- $\mathrm{kB}$ transcriptional activation [24].

\subsubsection{Chemopreventive Effect}

Hara-Terawaki et al. investigated the effect of flavan-3-ol microbial metabolites on the proliferation of human cervical cells [25]. Among all the metabolites produced from (-)-epigallocatechin, (-)-epigallocatechin gallate and (-)-epicatechin, 4-hydroxy-5-(3,4,5-trihydroxyphenyl)valeric acid, 5-(3,4,5-trihydroxyphenyl)valeric acid, and 5-(3,4-dihydroxyphenyl)valeric acid showed inhibitory activity on cell proliferation, relative to a negative control set at 100 (DMSO) of $71.9 \%, 13.5 \%$, and $53.9 \%$, respectively, at $50 \mu \mathrm{g} / \mathrm{mL}$ [25]. Therefore, the authors suggested that the presence of three hydroxyl groups and the aliphatic side chain could be involved in the anti-proliferative effect of the microbial metabolites [25].

A phenyl- $\gamma$-valerolactone, 5-( $3^{\prime}, 4^{\prime}, 5^{\prime}$-trihydroxyphenyl)- $\gamma$-valerolactone, showed a modest anti-proliferative effect in androgen-dependent human prostate cancer cells (LNCaP), with $\mathrm{IC}_{50}=117 \mu \mathrm{M}$ [26]. Moreover, the dihydrotestosterone-induced nuclear translocation of androgen receptor, known to play a key role on prostate cancer development and progression, was suppressed after $100 \mu \mathrm{M}$ treatment with the microbial metabolite [26].

\subsubsection{Immunostimulatory Activity}

Some of the positive effects of the intermediate microbial metabolites from flavan-3-ols seem to be as well mediated by direct stimulation of the immune system. In this regard, Kim et al. reported that 5 -( $3^{\prime}, 5^{\prime}$-dihydroxyphenyl)- $\gamma$-valerolactone plays an important role on immunostimulation, because the splenic NK cell cytotoxic activity against murine lymphoma YAC-1 cells was significantly increased after its oral administration $(10 \mathrm{mg} / \mathrm{kg})$ in comparison to the control and (-)-epigallocatechin treatment groups [27]. In addition, 5-(3',5'-dihydroxyphenyl)- $\gamma$-valerolactone upregulated the splenic production of IFN- $\gamma$, a T cell growth factor and effector of $\mathrm{CD} 4^{+} \mathrm{T}$ cells [27]. $\mathrm{CD} 4^{+} \mathrm{T}$ cell activity also increased 
after incubation with $10 \mu \mathrm{M}$ 5-(3',5'-dihydroxyphenyl)- $\gamma$-valerolactone for $72 \mathrm{~h}$, as well as it did with other microbial metabolites lacking the $4^{\prime}$-hydroxyphenyl group on the $\mathrm{B}$ ring [27].

\subsubsection{Neuroprotective Effect}

The in vitro stimulation of nerve cell proliferation and differentiation by phenyl- $\gamma$-valerolactones was recently reported by Unno et al. [28]. Particularly, only 0.05 $\mu \mathrm{M}$ 5-(3',5'-dihydroxyphenyl)- $\gamma$-valerolactone could enhance human SH-SY5Y neuroblastoma cell number, but at concentrations that were higher or equal to $1.0 \mu \mathrm{M}$, the effect was reduced [28]. The same concentration of the microbial metabolite, including its sulfated form, increased the length and number of neurites in SH-SY5Y as compared to control cells, whereas the glucuronide form could only increase the number of neurites [28].

\subsection{Phenolic Acids}

Table 2 presents the biological activities reported for smaller phenolic acids result of microbial catabolism of flavan-3-ols.

Table 2. Biological activity of phenolic acids. ${ }^{1}$

\begin{tabular}{|c|c|c|c|c|}
\hline Test/Model & Microbial Metabolite & $\begin{array}{c}\text { Concentration/ } \\
\text { Dose }\end{array}$ & Results & Ref. \\
\hline \multicolumn{5}{|c|}{ Anti-adhesive activity } \\
\hline $\begin{array}{l}\text { Beta cell function of Min6 pancreatic } \\
\text { beta cells incubated with cholesterol }\end{array}$ & 3,4-DHPA & $10-250 \mu \mathrm{M}$ & $\begin{array}{l}\text { 3,4-DHPA prevented impaired insulin } \\
\text { secretion induced by cholesterol by protecting } \\
\text { pancreatic beta cells against oxidative stress, } \\
\text { apoptosis and mitochondrial dysfunction. }\end{array}$ & [35] \\
\hline $\begin{array}{l}\text { Insulin signalling and glucose } \\
\text { uptake and production in rat renal } \\
\text { NRK-52E cells }\end{array}$ & $\begin{array}{l}\text { 2,3-DHB; 3,4-DHPA; } \\
\text { 3-HPP and VA }\end{array}$ & $20 \mu \mathrm{M}$ & $\begin{array}{c}\text { Glucose uptake and production decreased } \\
\text { after treatment with 2,3-DHB, and PEPCK } \\
\text { levels as well. IR and IRS-1 phosphorylated } \\
\text { and total protein levels were increased. The } \\
\text { inhibition of the PI3K/Akt pathway was } \\
\text { restrained. }\end{array}$ & [36] \\
\hline $\begin{array}{l}\text { Beta cell function and glucose } \\
\text { utilization in human skeletal muscle } \\
\text { and rat INS-1 beta cells }\end{array}$ & HA; HVA and 5-PVA & $5-100 \mu \mathrm{M}$ & $\begin{array}{l}\text { HA and 5-PVA stimulated glucose oxidation } \\
\text { in skeletal muscle and preserved skeletal } \\
\text { mitochondrial function after oxidative insult. } \\
\text { In beta cells, all metabolites induced } \\
\text { glucose-stimulated insulin secretion without } \\
\text { affecting beta cell mitochondrial respiration or } \\
\text { electron transport chain components' } \\
\text { expression. }\end{array}$ & [38] \\
\hline
\end{tabular}


Table 2. Cont.

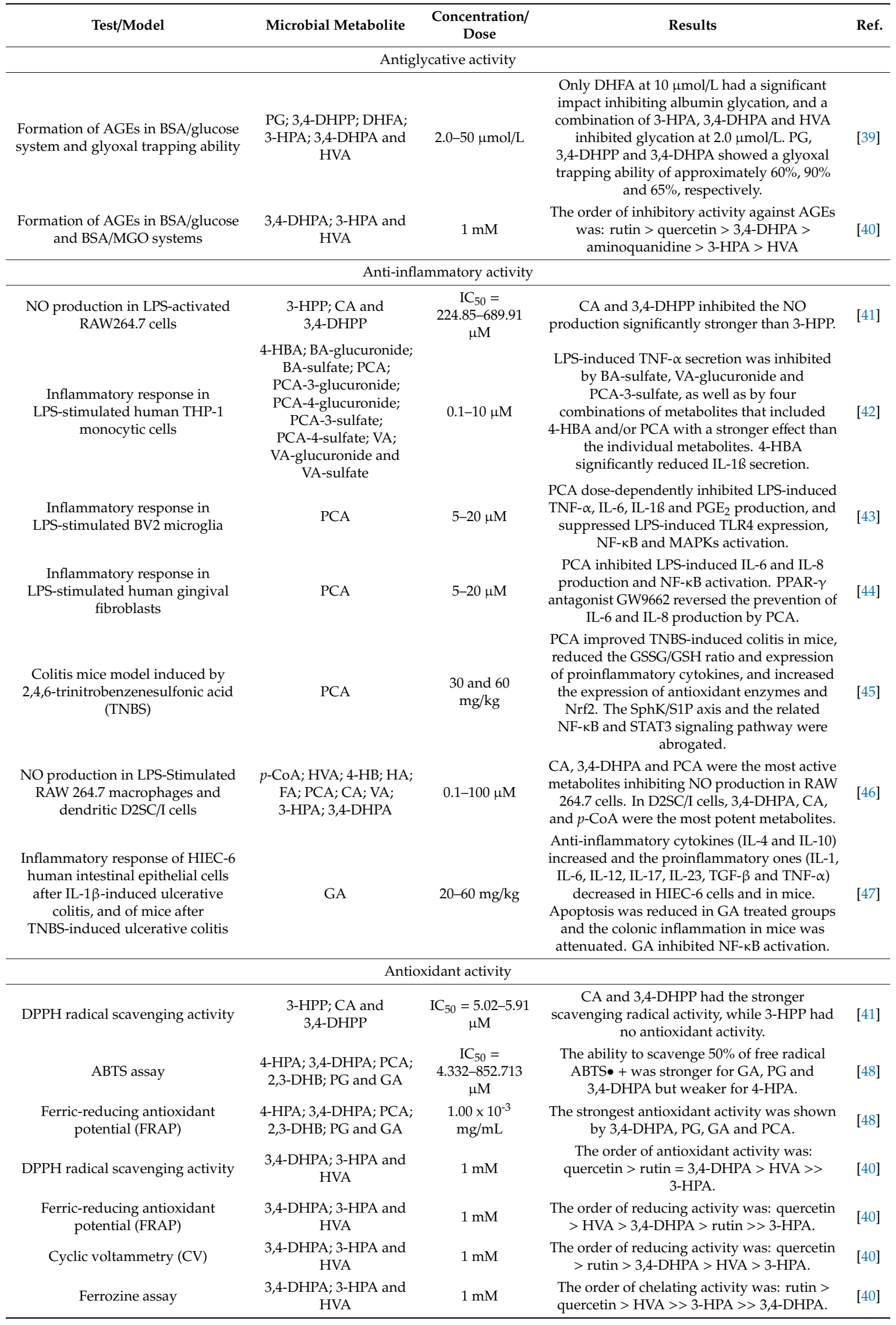


Table 2. Cont

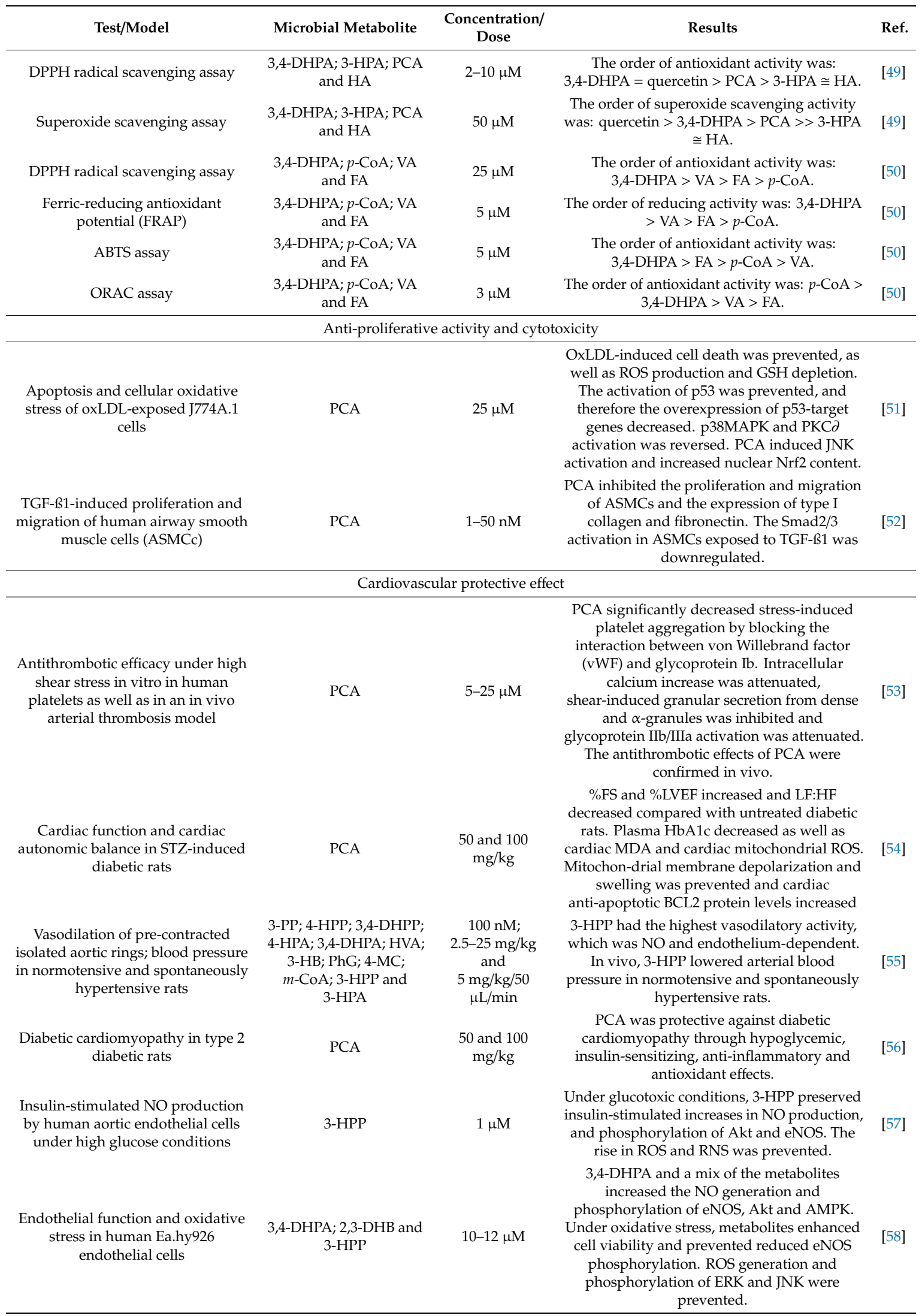


Table 2. Cont

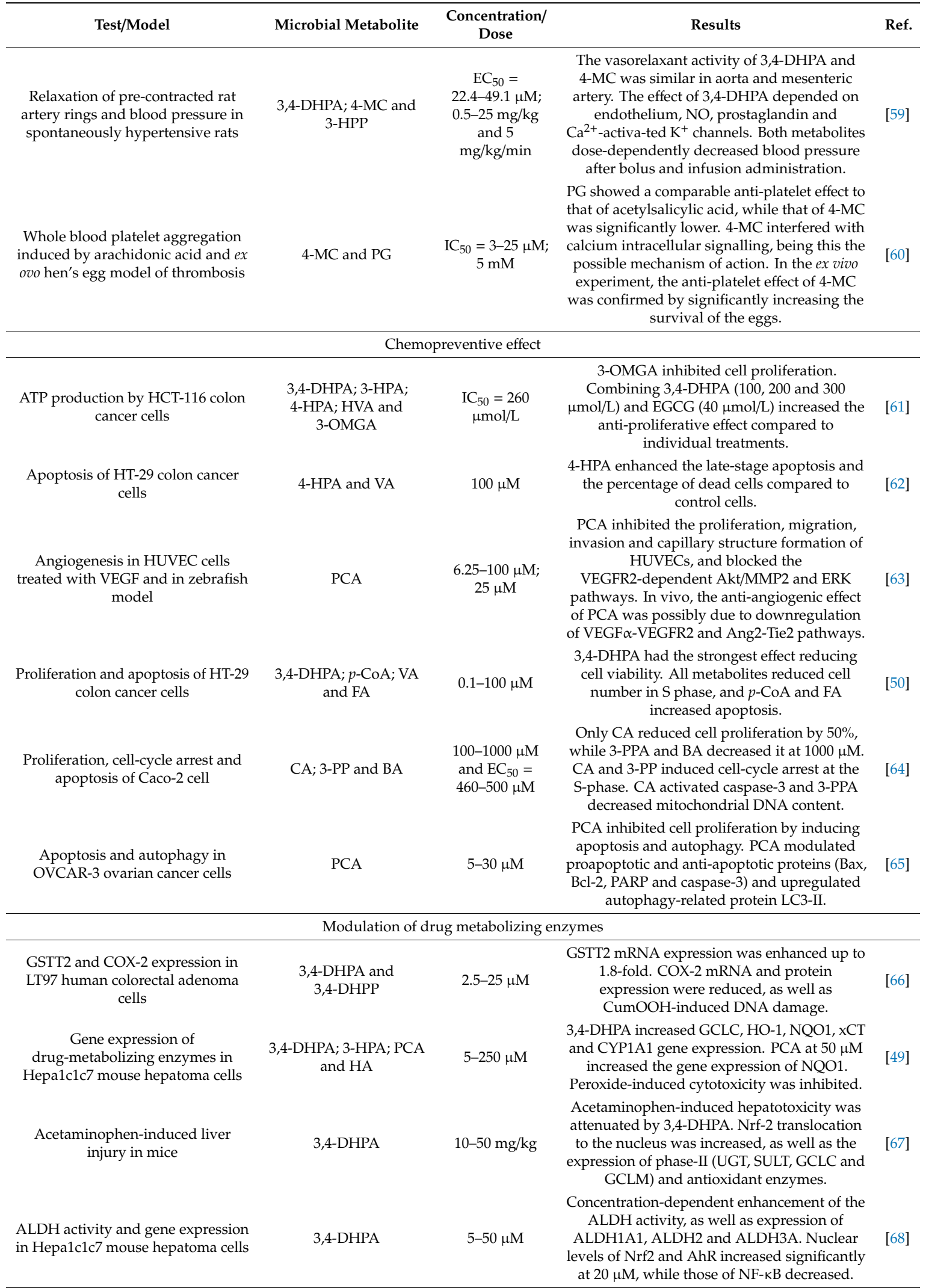


Table 2. Cont.

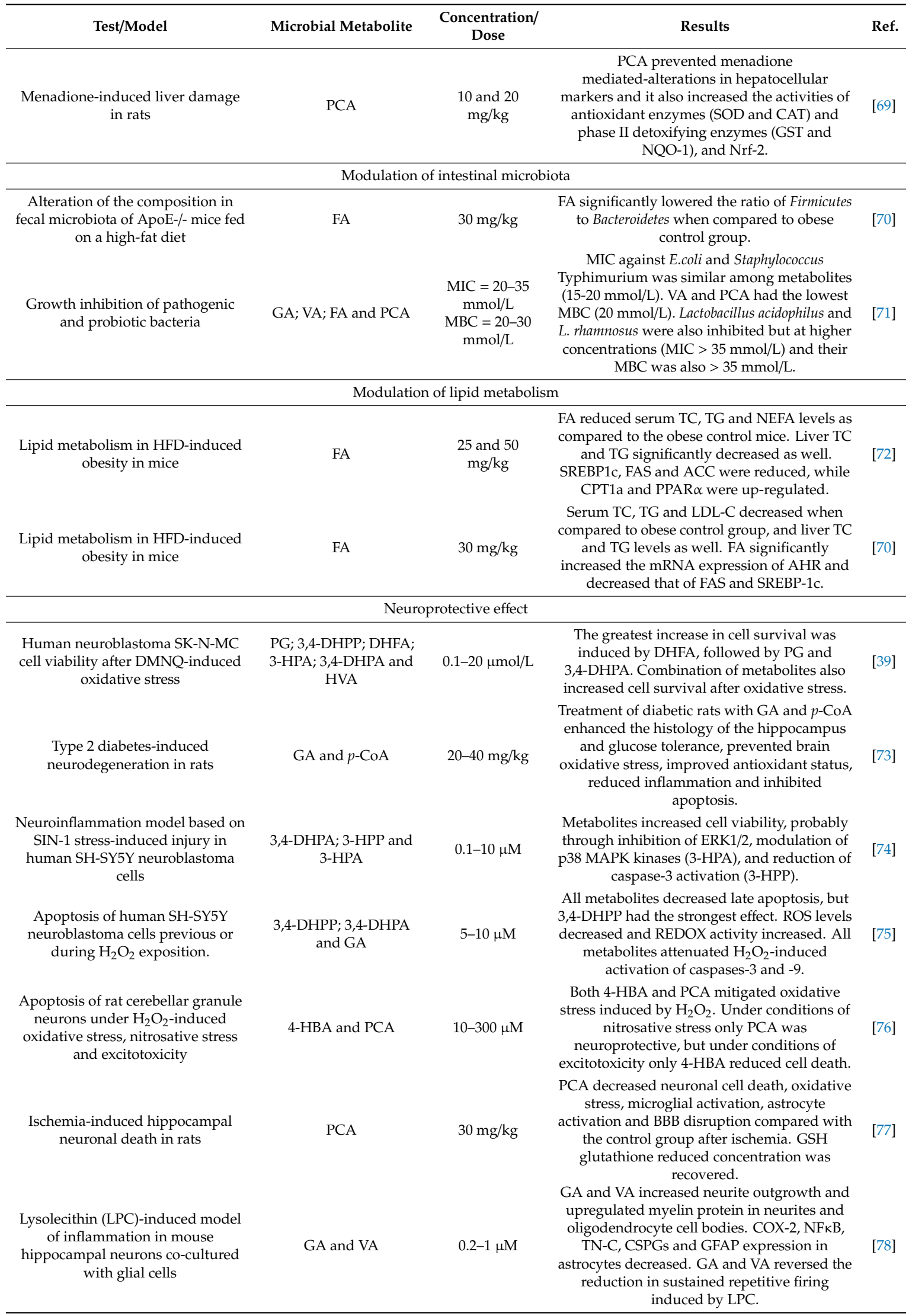


Table 2. Cont.

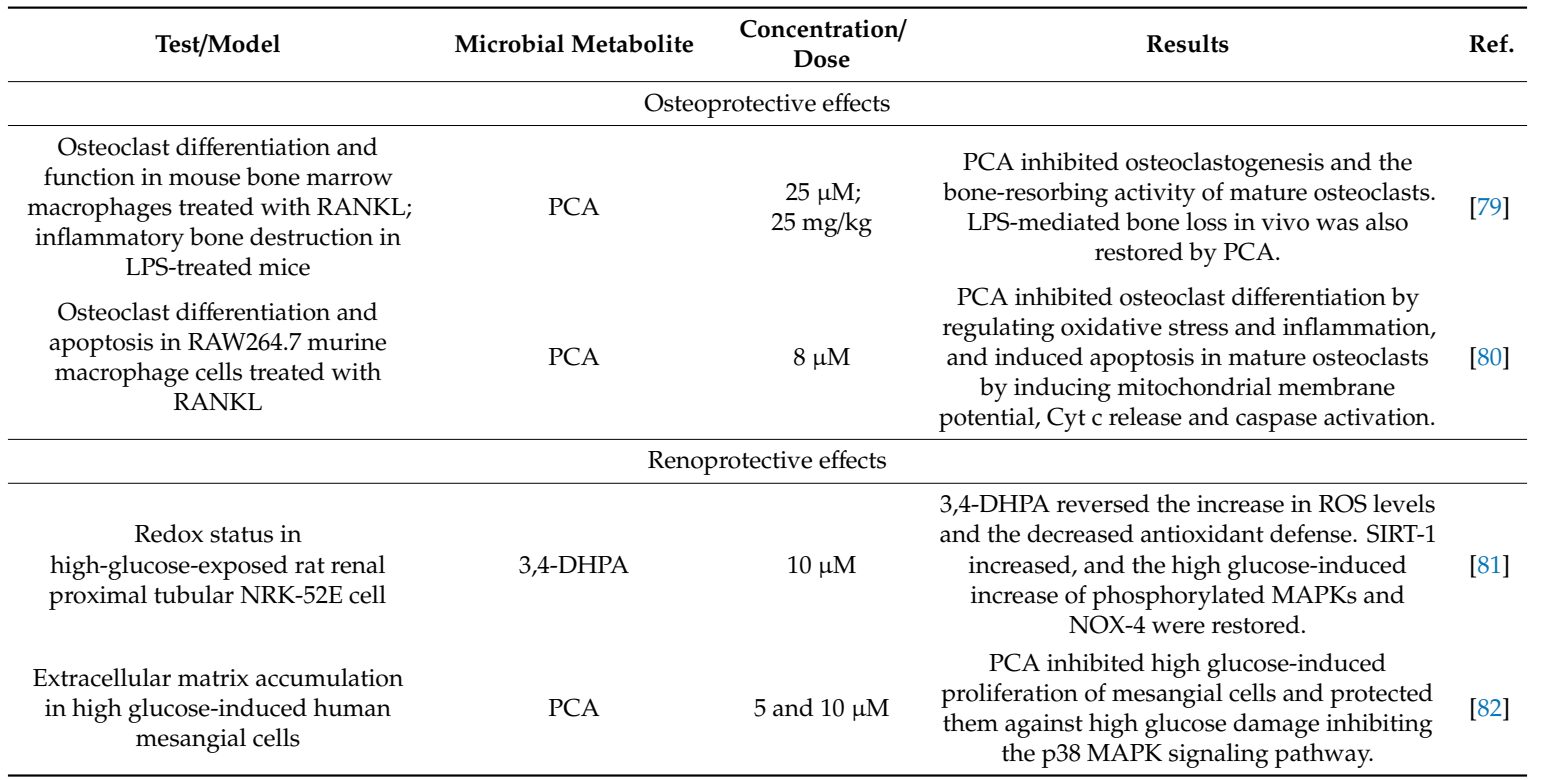

${ }^{1}$ ABTS: 2-azinobis-(3-ethylbenzothiazoline-6-sulphonate) radical cation; AGE: advanced glycation end-products; Akt: protein kinase B; ALDH: aldehyde dehydrogenase; AMPK: adenosine monophosphate-activated protein kinase; Ang2: angiotensin-2; AR: androgen receptor; BBB: blood-brain barrier; Bcl-2: B-cell lymphoma 2; BSA: bovine serum albumin; CAT: catalase; COX-2: cyclooxygenase-2; CSPG: chondroitin sulfate proteoglycans; CYP1A1: cytochrome P450 1A1; DMNQ: 2,3-dimethoxy-1,4-naphtoquinone; DMSO: dimethyl sulfoxide; DPPH: 2,2-diphenyl-1-picrylhydrazyl radical; $\mathrm{EC}_{50}$ : half maximal effective concentration; eNOS: endothelial nitric oxide synthase; ERK: extracellular signal-regulated kinases; FS: fractional shortening; GCLC: glutamate-cysteine ligase catalytic subunit; GCLM: glutamate-cysteine ligase modifier subunit; GFAP: glial fibrillary acidic protein; GLUT: glucose transporter; GPx: glutathione peroxidase; GSH: glutathione; GSIS: glucose-stimulated insulin secretion; GSK-3: glycogen synthase kinase-3; GST: glutathione S-transferase; GSTT2: glutathione S-transferase theta-2; HO-1: heme oxygenase 1; HUVEC: human umbilical vein endothelial cells; $\mathrm{IC}_{50}$ : half maximal inhibitory concentration; IL: interleukin; iNOS: inducible nitric oxide synthase; IR: insulin receptor; IRS-1: insulin receptor substrate 1; JNK: c-Jun N-terminal kinases; LC3: microtubule-associated proteins 1A/1B light chain 3B; LF:HF: low-frequency:high-frequency; LPC: lysolecithin; LPS: lipopolysaccharide; LVEF: left ventricular ejection fraction; MAPK: mitogen-activated protein kinase; MBC: minimal bactericidal concentration; MCP-1: monocyte chemoattractant protein 1; MGO: methylglyoxal; MIC: minimal inhibitory concentration; MMP2: matrix metalloproteinase-2; NF-kB: nuclear factor kappa-light-chain-enhancer of activated B cells; NK cells: natural killer cells; NO: nitric oxide; NOX-4: NADPH-oxidase-4; NQO1: NADH:quinone oxidoreductase-1; Nrf2: nuclear factor (erythroid-derived 2)-like 2; ORAC: oxygen radical absorbance capacity; oxLDL: oxidized LDL; PARP: poly (ADP-ribose) polymerase; PI3K: phosphatidylinositol-3-kinase; PEPCK: phosphoenolpyruvate carboxykinase; $\mathrm{PGE}_{2}$ : prostaglandin $\mathrm{E}_{2}$; PKC: protein kinase $\mathrm{C}$; PPAR $\gamma$ : peroxisome proliferator-activated receptor- $\gamma$; RANKL: receptor activator for nuclear factor $\mathrm{KB}$ ligand; RNS: reactive nitrogen species; ROS: reactive oxygen species; SGLT-2: sodium-glucose co-transporter-2; SIN-1: 3-morpholinosyndnomine; SIRT-1: sirtuin 1; SOD: superoxide dismutase; SphK/S1P: sphingosine kinase/sphingosine 1-phosphate; STAT-3: signal transducer and activator of transcription 3; STZ: streptozotocin; SULT: sulfotransferase; TGF-B: transforming growth factor beta; Tie: tyrosine kinase receptor; TLR-4: toll-like receptor 4; TN-C: Tenascin-C; TNF $\alpha$ : tumor necrosis factor; UGT: UDP-glucuronosyltransferase; VCAM: vascular cell adhesion molecule; VEGF: vascular endothelial growth factor; VEGR-2: vascular endothelial growth factor receptor 2; xCT: cystine/glutamate anti-porter. Flavan-3-ols and microbial metabolites. BA: benzoic acid; CA: caffeic acid; DHFA: dihydroferulic acid; EC: (-)-epicatechin; EGC: (-)-epigallocatechin; EGCG: (-)-epigallocatechin gallate; FA: ferulic acid; GA: gallic acid; HA: hippuric acid; HVA: homovanillic acid; $m$-CoA: m-coumaric acid; $p$-CoA: p-coumaric acid; PA: phenylacetic acid; PCA: protocatechuic acid; PG: pyrogallol; PhG: phloroglucinol; VA: vanillic acid; 3-HB: 3-hydroxybenzoic acid; 4-HB: 3-HPA: 3-hydroxyphenylacetic acid; 4-HPA: 4-hydroxyphenylacetic acid; 3-HPP: 3-hydroxyphenylpropionic acid 4-HPP: 3-(4-hydroxyphenyl)-propionic acid; 4-MC: 4-methylcatechol; 3-OMGA: 3-O-methylgallic acid; 3-PP: 3-phenylpropionic acid; 2,3-DHB: 2,3-dihydroxybenzoic acid; 3,4-DHPA: 3,4-dihydroxyphenylacetic acid; 3,4-DHPP: 3,4-dihydroxyphenylpropionic acid; 3,5-DHPP: 3-(3',5'-dihydroxyphenyl)propionic acid.

\subsubsection{Anti-adhesive Activity}

The inhibitory activity against the adherence of uropathogenic bacteria E. coli to uroepithelial cells has also been tested with low molecular weight phenolics. In particular, catechol, benzoic acid, vanillic acid, phenylacetic acid, and 3,4-dihydroxyphenylacetic acid (3,4-DHPA) inhibited E. coli adherence in a concentration-dependent manner from 100 to $500 \mu \mathrm{M}$ [32]. The inhibitory effect appeared to be 
more pronounced in the case of gallic acid, phenylacetic acid, and 3,4-DHPA, which induced up to $40.6 \pm 20.2 \%, 40.6 \pm 10.1 \%$, and $37.0 \pm 20.5 \%$ adherence inhibition at $500 \mu \mathrm{M}$, respectively [32].

\subsubsection{Antidiabetic Effect}

The antidiabetic effects of various microbial metabolites from flavan-3-ols have been investigated from different perspectives, and the involved mechanisms are apparently not only related to their antioxidant properties, but also to their ability to modulate different signalling pathways.

Scazzocchio et al. assessed the role of protocatechuic acid in the glucose transport in adipocytes [33]. Incubation of the metabolite at $100 \mu \mathrm{M}$ for $18 \mathrm{~h}$ with human and murine adipocytes treated with oxidized LDL (oxLDL) showed that protocatechuic acid significantly reversed the detrimental effects of oxLDL on glucose uptake and glucose transporter type 4 (GLUT4) translocation. In addition, when both adipocytes were insulin-stimulated and also when human adipocytes were not insulin-stimulated, protocatechuric acid significantly removed the detrimental effect of oxLDL on adiponectin secretion [33]. Glucose uptake increased in a significant and concentration-dependent manner in non-oxLDL-treated human and murine adipocytes in the absence of insulin up to $40 \%$ and $60 \%$, respectively [33]. These results suggested an insuline-like activity. The reduced peroxisome proliferator-activated receptor- $\gamma$ $(\mathrm{PPAR} \gamma)$ mRNA expression and activity induced by oxLDL was also counteracted, and its inhibition blocked both the adiponectin and GLUT4 upregulation, which suggests a direct involvement on the insuline-like activity of protocatechuic acid [33].

The effect of low molecular weight phenolics on beta cell functionality has also been assessed. Fernández-Millán et al. reported a significant increase in glucose-induced insulin secretion in INS-1E pancreatic beta cells and isolated rat islets after treatment with 3,4-DHPA and 3-hydroxyphenylpropionic acid (3-HPP) at low concentrations (5 and $1 \mu \mathrm{M}$, respectively) [34]. Moreover, in the presence of oxidative stress that was induced by t-BOOH, both 3,4-DHPA and 3-HPP restored glucose-stimulated insulin secretion to control levels and significantly reduced $\mathrm{t}-\mathrm{BOOH}$-induced cell death as well as ROS and carbonyl group production [34]. Protein kinases, specifically protein kinase C (PKC) and extracellular signal-regulated kinases (ERK), could be involved, since their phosphorylation levels were enhanced after treatment and their pharmacological inhibition blocked the increased insulin secretion that was induced by the metabolites [34].

Carrasco-Pozo et al. evaluated the protective effect of 3,4-DHPA on Min6 pancreatic beta cells dysfunction that was induced by high cholesterol, and the metabolite at $250 \mu \mathrm{M}$ could indeed prevent the decrease in insulin secretion induced by high cholesterol [35]. Furthermore, it prevented the cholesterol-induced cytotoxicity and apoptosis in a concentration-dependent manner, and also prevent oxidative stress and mitochondrial dysfunction [35]. Nuclear factor (erythroid-derived 2)-like 2 (Nrf2) translocation to the nucleus was increased by around six-fold relative to control, which suggests that it contributes to the antioxidant protection exerted by 3,4-DHPA [35].

Recently, Bitner et al. reported that hippuric acid and homovanillic acid, as well as the phenylvaleric acid 5-phenylvaleric acid, more effectively enhanced glucose-stimulated insulin secretion (GSIS) in beta cells than (-)-epicatechin at concentrations between 5 and $100 \mu \mathrm{M}$ (hippuric acid between 5 and $50 \mu \mathrm{M})$ [38]. Contrary to (-)-epicatechin, the microbial metabolites enhanced GSIS without enhancing beta cell mitochondrial respiration or increasing expression of mitochondrial electron transport chain components [38]. In addition to the stimulation of beta cell function, the microbial metabolites stimulated glucose utilization in skeletal muscle and they preserved mitochondrial function after insulation [38].

Álvarez Cilleros et al. investigated how flavan-3-ol-derived low molecular weight phenolics influenced the mechanisms related to the glucose homeostasis in rat renal NRK-52E cells since kidneys are involved in the maintenance of glucose homeostasis [36]. The authors found out that 2,3-dihydroxybenzoic acid (2,3-DHB) at $20 \mu \mathrm{M}$ reduced cellular glucose uptake in a similar way to the sodium-glucose co-transporter-2 (SGLT-2) antagonist phlorizin, without altering the expression levels of SGLT-2 and glucose transporter-2 (GLUT-2) [36]. Glucose production was significantly 
reduced and the levels of the gluconeogenic enzyme phosphoenolpyruvate carboxykinase (PEPCK) were also reduced [36]. In addition to the effects on glucose uptake and production, the effect of the microbial metabolite on the activation of proteins from the insulin signalling pathway was evaluated. 2,3-DHB significantly increased insulin receptor (IR), insulin receptor substrate 1 (IRS-1) tyrosine phosphorylated, and total protein levels, as well as the phosphorylated levels of protein kinase B (Akt) and glycogen synthase kinase-3 (GSK3), and subsequently reduced the glycogen synthase (GS) phosphorylated levels [36]. Moreover, the authors showed that Akt was involved in the modulation by 2,3-DHB of both PEPCK levels and glucose production in the NRK-52E cells [36].

Similarly, in another study from Álvarez-Cilleros et al., when renal tubular NRK-52E cells were treated with high glucose levels, 3,4-DHPA at $10 \mu \mathrm{M}$ restored the induced alteration in glucose uptake and production and increased tyrosine phosphorylated and total levels of IR [37]. Moreover, it restrained the inhibition of the phosphatidylinositol-3-kinase (PI3K)/Akt pathway that was involved in the insulin signalling cascade and counteracted the high glucose-induced downregulation on 5'-AMP-activated protein kinase (AMPK) phosphorylation and upregulation on PEPCK [37]. When Akt and AMPK were inhibited the protective effect of 3,4-DHPA was abrogated, which suggests that they play a key role on the preservation of renal tubular functionality, the modulation of the glucose homeostasis by the metabolites, together with the attenuation of the insulin signalling blockade [37].

\subsubsection{Antiglycative Activity}

Advanced glycation end-products (AGEs) contribute to the occurrence of several pathologies, such as diabetes and rheumatoid arthritis [83]. For this reason, the effect of phenolics against their formation has been evaluated. Dihydroferulic acid has been shown to significantly inhibit albumin glycation at a concentration of $10 \mu \mathrm{mol} / \mathrm{L}$, and the combination of 3-hydroxyphenylacetic acid (3-HPA), 3,4-DHPA, and homovanillic acid at $2.0 \mu \mathrm{mol} / \mathrm{L}$ has also shown this [39]. 3,4-DHPA at $1 \mathrm{mM}$ exerted an inhibitory activity against AGEs that was significantly lower than that of rutin and quercetin, but significantly higher than the positive control aminoquanidine, 3-HPA and homovanillic acid [40].

\subsubsection{Anti-inflammatory Activity}

Prevention of inflammation by microbial low molecular weight phenolics has been shown to occur by modulating the mediators of inflammation and additionally the signal transduction pathways involved.

Yang et al. reported that trans-caffeic acid and 3,4-dihydroxyphenylpropionic acid (3,4-DHPP) inhibited the NO production in LPS-activated RAW264.7 cells $\left(\mathrm{IC}_{50}=224.85-689.91 \mu \mathrm{M}\right)$ [41]. In the same cellular model and in dendritic D2SC/I cells, Ho et al. reported the same anti-inflammatory effects for trans-caffeic, and for the metabolites 3,4-DHPA, protocatechuic acid, and $p$-coumaric acid [46].

The secretion of another inflammatory mediator, TNF- $\alpha$, induced by LPS in THP-1 monocytes, was reduced by benzoic acid-sulfate, vanillic acid-glucuronide, and protocatechuic acid-3-sulfate in a study from di Gesso et al. [42]. Moreover, four different combinations of metabolites that included 4-hydroxybenzoic acid or protocatechuic acid or both could also significantly reduce TNF- $\alpha$ secretion, but, interestingly, to a greater extent than the metabolites alone, which showed no significant effect [42].

Wang et al. showed that protocatechuic acid at 5, 10, and $20 \mu \mathrm{M}$ dose-dependently inhibited the production of the inflammatory mediators TNF- $\alpha$, interleukin 6 (IL-6), interleukin 1 beta (IL-1B), and prostaglandin $\mathrm{E}_{2}\left(\mathrm{PGE}_{2}\right)$ in LPS-stimulated BV2 microglia [43]. The LPS-induced expression of toll-like receptor 4 (TLR4), activation of NF- $\mathrm{KB}$, and mitogen-activated protein kinases (MAPKs) in BV2 microglial cells was furthermore suppressed by protocatechuic acid, which suggests that these signaling pathways are actively involved in its anti-inflammatory activity [43]. The same metabolite at 5,10 , and $20 \mu \mathrm{M}$ was also shown to inhibit LPS-induced production of IL-6 and interleukin 8 (IL-8) in human gingival fibroblasts, secondarily to its ability to activate PPAR- $\gamma$ [44].

In a 2,4,6-trinitrobenzenesulfonic acid (TNBS) model of rodent inflammatory bowel disease, protocatechuic acid administered at 30 and $60 \mathrm{mg} / \mathrm{kg}$ improved the TNBS-induced colitis and reduced 
oxidative stress that was measured as GSSG/GSH ratio [45]. The antioxidant enzymes expression increased after treatment with protocatechuic acid when compared to the TNBS group and additionally the transcription factor Nrf2 protein levels [45]. The TNBS-induced increase in colonic expression of the inflammatory markers IL-6, TNF- $\alpha$, IL- $1 \beta$, and cyclooxygenase-2 (COX-2) was reversed [45]. The SphK/S1P signaling pathway seems to play a key role, since TNBS-induced an increase in mRNA levels, an increase in protein concentration and immunohistochemical labelling for SphK1 was prevented by protocatechuic acid [45]. Similarly, the increase in S1P production and expression of S1P receptor 1 and S1P phosphatase 2 were significantly reversed [45]. Related signaling pathways might be also involved, since protocatechuic acid reversed the TNBS-induced increase of phosphorylated signal transducer and the activator of transcription 3 (STAT3), NF- $\mathrm{kB}$ p65 subunit expression, and phosphorylation of Akt and ERK [45]. In a similar model, gallic acid that was given at 20-60 mg/kg improved the TNBS-induced colitis in mice and inhibited inflammation reducing proinflammatory cytokines, such as IL-1 and IL-6, and increased the anti-inflammatory cytokines via inhibiting the NF-KB pathway [47].

\subsubsection{Antioxidant Activity}

Low molecular weight phenolics have been investigated for their antioxidant activity in vitro through different assays that are able to measure their scavenging capacity against non-biological radicals, including 2,2-diphenyl-1-picrylhydrazyl radical assay (DPPH• assay), the 2,2-azinobis-(3-ethylbenzothiazoline-6-sulphonate) radical cation assay (ABTS $\bullet+$ assay), and ferric reducing antioxidant power (FRAP assay), as well as their scavenging capacity against biological oxidants, such as superoxide radicals scavenging (O2--).

One of the studied microbial metabolites of flavan-3-ols showing high antioxidant activity is 3,4-DHPA. This metabolite was able to scavenge ABTS [48], DPPH $[40,49,50]$, as well as reduce $\mathrm{Fe}^{3+}$ ions to $\mathrm{Fe}^{2+}$ ions $[40,48,50]$, being effective, even at low concentrations, like $5 \mu \mathrm{M}$, and, in some cases, showing an equivalent scavenging activity to flavonoids, like rutin or quercetin [40,49].

Other derivatives of microbial catabolism of flavan-3-ols that have also shown antioxidant activity are caffeic acid [41], 3,4-DHPP [41], gallic acid [48], pyrogallol [48], homovanillic acid [40], protocatechuic acid [49], as well as vanillic and ferulic acids [50]. In some studies, metabolites, such as 3-HPA [40,49], 3-HPP [41], and hippuric acid [49], showed no antioxidant activities.

Although the evaluation of the antioxidant activity of all these compounds has been performed while using different assays, as well as at different concentrations and conditions, it is clear that low molecular weight phenolics can act as antioxidants. As suggested by many authors, the number of hydroxyl groups can be involved in their antioxidant activity.

\subsubsection{Anti-proliferative Activity and Cytotoxicity}

The anti-proliferative activity of low molecular weight phenolics has been assessed in a variety of cellular models, including murine macrophages as well as human cancer cell lines. For a better classification of the biological activities of metabolites, the studies assessing the anti-proliferative activity on human cancer cell lines are presented in a following section about chemopreventive effects.

In a study from Varì et al., protocatechuic acid at a concentration of $25 \mu \mathrm{M}$ counteracted the cytostatic and cytotoxic effect of oxLDL in J774A.1 macrophages [51]. The oxLDL induced an increased apoptosis as well as oxidative stress, and both were reduced after treatment with the metabolite, although the ROS production could only be abolished during the first six hours of treatment [51]. The metabolite at $25 \mu \mathrm{M}$ could reduce the oxLDL-induced activation of $\mathrm{p} 53$ protein and counteract the overexpression of the main p53 target genes: p66Shc and Bax [51]. The activation of the c-Jun N-terminal kinases (JNK)/Nrf2 pathway could play a key role in the anti-apoptotic effects of protocatechuic acid, since its inhibition caused a change in the expression of phosphorylated p53, Bax and the active form of caspase-3 comparable to levels that were found in cells only treated with oxLDL [51]. This inhibition also suppressed the effect of protocatechuic acid on the reduction of oxLDL-induced ROS levels [51]. 
Liu et al. also recently reported the anti-proliferative effects of protocatechuic acid in preventing or treating asthma airway remodeling, since it suppressed the proliferation of airway smooth muscle cells and extracellular matrix protein deposition in transforming growth factor-beta1 (TGF-B1)-mediated airway smooth muscle cells via the inactivation of Smad2/3 signaling pathway [52].

\subsubsection{Cardiovascular Protective Effect}

Low molecular weight phenolics could have a positive effect on the prevention of cardiovascular disease through protection of the heart and the endothelial function, through antithrombotic effects, as well as through their previously presented anti-inflammatory activity.

On the one hand, the anti-platelet and antithrombotic potential of protocatechuic acid were confirmed in a study from Kim et al. [53]. This metabolite at concentrations between 5 and $25 \mu \mathrm{M}$ significantly decreased stress-induced platelet aggregation in isolated human platelets, which was mediated by blocking the interaction between von Willebrand factor (vWF) and platelet receptor glycoprotein $\mathrm{Ib}$ [53]. The increase of intracellular calcium induced by shear stress was dose-dependently attenuated by protocatechuic acid. Moreover, this metabolite inhibited shear-induced granular secretion from dense and $\alpha$-granules and attenuated GP Ilb/IIIa activation. Interestingly, protocatechuic acid did not inhibit platelet aggregation induced by other endogenous agonists [53]. In an in vivo rat arterial thrombosis model, the antithrombotic effects of PCA were confirmed and this metabolite did not show increased risk of bleeding [53].

Similarly, 4-methylcatechol has been reported to also have anti-platelet effects [60]. When testing its effect on whole blood platelet aggregation induced by arachidonic acid, this metabolite was much more active than acetylsalicylic acid ( $\mathrm{IC}_{50}=3 \mu \mathrm{M}$ vs. $\mathrm{IC}_{50}=25 \mu \mathrm{M}$, respectively) [60]. This could be confirmed by the authors in an ex ovo thrombotic model that mimics the in vivo situation [60]. Moreover, 4-methylcatechol was shown to interfere with calcium intracellular trafficking, and this seemed to be its main mechanism of action. As the authors suggest, the methyl group probably does not play any role in the anti-platelet potential, but the hydroxyl groups in positions 1 and 2 seem to be important [60].

On the other hand, the cardioprotective effects have been attributed to protocatechuic acid by Semaming et al. [54]. When administered to type 1 diabetic rats at a dosage of 50 and $100 \mathrm{mg} / \mathrm{kg}$, it significantly increased the fractional shortening and the left ventricular ejection fraction when compared to non-treated diabetic rats after 8 and 12 weeks, and the effects were partially comparable to those after treatment with insulin [54]. Moreover, the low-frequency:high-frequency ratio was significantly decreased when compared with the non-treated diabetic rats. The authors also found a significant decrease of plasma $\mathrm{HbA1c}$ and cardiac MDA levels, an improvement of cardiac mitochondrial function, and an increase in anti-apoptotic BCL2 expression [54].

In another study, the same metabolite was shown to have a positive effect on diabetic cardiomyopathy in type 2 diabetic rats when orally administered (50 and $100 \mathrm{mg} / \mathrm{kg}$ ) [56]. Protocatechuic acid exerted hypoglycemic and insulin-sensitizing activities via the stimulation of IRS1/PI3K/AKT/AMPK/GLUT4/P 38 signaling pathway in the skeletal muscle and anti-inflammatory effects mediated by the downregulation of the poly (ADP-ribose) polymerase (PARP)/PKC/NF- $\mathrm{KB}$ signaling cascade in the myocardial tissue [56]. Moreover, antioxidant and radical scavenging effects in the myocardial tissue of type 2 diabetic rats were also attributed to the administration of protocatechuic acid [56].

The vasodilatory effect of microbial metabolites has been well assessed. Najmanová et al. performed an in vitro study where 3-HPP at $100 \mathrm{nM}$ exerted the strongest vasodilatory activity on isolated aortic rings from all tested metabolites, and both endothelium and NO were found to play a role [55]. In a study from Pourová et al., 3,4-DHPA and 4-methylcatechol were reported to induce vasorelaxation in pre-contracted aortic rings and mesenteric artery [59]. The metabolites exerted similar effects in both aortic rings (96.5\% and $96.8 \%$ relaxation, respectively) and the mesenteric artery (101.4\% and $98.3 \%$ relaxation, respectively) [59]. The half maximal effective concentrations of 
3,4-DHPA to induce vasorelaxation in aortic rings and mesenteric artery were $\mathrm{EC}_{50}=22.4 \pm 1.3 \mu \mathrm{M}$ and $\mathrm{EC}_{50}=34.2 \pm 5.6 \mu \mathrm{M}$, respectively [59]. For 4-methylcatechol, these were $\mathrm{EC}_{50}=49.1 \pm 3.3 \mu \mathrm{M}$ and $\mathrm{EC}_{50}=30.5 \pm 1.4 \mu \mathrm{M}$, respectively [59]. Unlike 4-methylcatechol, the vasorelaxant effects of 3,4-DHPA were partially dependent on endothelium and reduced after atropine administration [59].

In vivo models in rats show a decrease of arterial blood pressure in both normotensive and spontaneously hypertensive rats after bolus $(2.5-25 \mathrm{mg} / \mathrm{kg})$ and $5-\mathrm{min}$. infusion $(5 \mathrm{mg} / \mathrm{kg} / 50 \mu \mathrm{L} / \mathrm{min}$., mimicking gastrointestinal absorption) administration of 3-HPP [55]. Similarly, the administration of 3,4-DHPA and 4-methylcatechol as a bolus or as an infusion dose-dependently decreased blood pressure in rats [59].

3-HPP was also reported to be beneficial for endothelial function by Qian et al. [57]. Particularly, $1 \mu \mathrm{M} 3-\mathrm{HPP}$ was able to maintain the NO production stimulated by insulin in human aortic endothelial cells under glucotoxic conditions, and additionally to increase endothelial nitric oxide synthase (eNOS) and Akt phosphorylation [57].

Álvarez Cilleros et al. also reported an increased NO production too, but, in this case after the treatment of EA.hy 927 human endothelial cells with $10 \mu \mathrm{M} 3,4$-DHPA or with a mix of that metabolite with 2,3-dihydroxybenzoic acid (2,3-DHB) and 3-HPP (12 $\mu \mathrm{M})$ [58]. AMPK and Akt seem to be key mediators, since their inhibition blocked the NO production as well as eNOS phosphorylation [58]. Under oxidative stress that is induced by $\mathrm{t}-\mathrm{BOOH}$, both 3,4-DHPA and the mix of the metabolites reversed the induced endothelial dysfunction by preventing increased ROS generation and the activation of signalling pathways related to oxidative stress [58].

\subsubsection{Chemopreventive Effect}

The potential cancer preventing effect of low molecular weight phenolics has often been studied in in vitro models of intestinal cell lines. Henning et al. found that the proliferation of HCT116 colon cancer cells was inhibited by 3,4-DHPA and 3-O-methylgallic acid [61]. The concentrations of 3,4-DHPA that were needed for a significant inhibition of cell proliferation were 200 and $300 \mu \mathrm{mol} / \mathrm{L}$, but the concentration exhibiting 50\% inhibition was higher than $400 \mu \mathrm{mol} / \mathrm{L}$. However, 3-O-methylgallic acid, had a IC $50=260 \mu \mathrm{mol} / \mathrm{L}$ [61]. When 3,4-DHPA was combined with epigallocatechin, the inhibitory effects significantly increased when compared to the individual treatments [61].

Rosa et al. also reported 3,4-DHPA to induce the largest reduction of cell viability of HT-29 human colon adenocarcinoma cells at concentrations between 2.5 and $100 \mu \mathrm{M}$ (up to $66 \%$ reduction) [50]. $p$-Coumaric acid, vanillic acid, and ferulic acid could also reduce cell viability [50]. The metabolites modulated the cell cycle, since 3,4-DHPA, p-coumaric acid, vanillic acid (10 and $100 \mu \mathrm{M})$, and additionally ferulic acid $(10 \mu \mathrm{M})$ decreased the cell number in S phase [50]. Relative apoptosis rate data showed that $p$-coumaric acid and ferulic acid at $10.0 \mu \mathrm{M}$ promoted increased apoptosis [50]. In a study from López de las Hazas et al., late-stage apoptosis of HT-29 colon cancer cells was reported to be also induced by 4-hydroxyphenylacetic acid [62].

The anti-proliferative activity, cell cycle arrest and apoptosis of caffeic acid, 3-phenylpropionic acid (3-PP), and benzoic acid in Caco-2 human colon cancer cells were tested by Sadeghi Ekbatan et al. [64]. Only caffeic acid reduced cell proliferation by $50 \%\left(\mathrm{EC}_{50}=460 \pm 21.88 \mu \mathrm{M}\right)$, while 3-PP and benzoic acid reduced it at a concentration of $1000 \mu \mathrm{M}$ [64]. Cell-cycle arrest was induced at the S-phase by caffeic acid at $100 \mu \mathrm{M}$ and by 3-PP at $500 \mu \mathrm{M}$ [64]. Regarding apoptosis, caffeic acid at $1000 \mu \mathrm{M}$ activated caspase-3, and the mitochondrial DNA content was reduced by 3-PP at $1000 \mu \mathrm{M}$ [64].

Since angiogenesis, the process by which new blood vessels are formed is involved in the progression of tumors, Hu et al. evaluated the anti-angiogenic activity of protocatechuic acid in vitro as well as in an in vivo animal model [63]. In the in vitro model with human umbilical vein endothelial cells (HUVEC), protocatechuic acid inhibited the vascular endothelial growth factor (VEGF)-induced proliferation, the formation of capillary tubes, and the migration and invasion of HUVECs [63]. The mechanisms that are involved might be related to its ability to attenuate ROS production $(6.25-100 \mu \mathrm{M})$ as well as by interfering with VEGF-dependent Akt/MMP2 and ERK pathways [63]. The in vivo model 
in zebrafish showed that, at $25 \mu \mathrm{M}$, protocatechuic acid also had a significant anti-angiogenic effect when compared with the control group, possibly through downregulation of the angiogenesis-related signal transduction pathways of VEGF $\alpha$-VEGF Receptor 2 and angiotensin 2-Tie2 receptor [63].

Protocatechuic acid at up to $30 \mu \mathrm{M}$ was furthermore able to reduce cell viability of ovarian cancer cells OVCAR-3 in a dose-dependent manner $\left(\mathrm{IC}_{50}=10.7 \mu \mathrm{M}\right)$ and it induced apoptosis [65]. Furthermore, it induced the cell cycle arrest in $\mathrm{G}_{2} / \mathrm{M}$ phase [65]. The increased apoptosis was accompanied by the activation of PARP and caspase-3, the upregulation of Bax and downregulation of B-cell lymphoma 2 (Bcl-2) in OVCAR-3 cells [65]. Additionally, autophagy-related protein LC3-II was upregulated and the intracellular ROS levels decreased, while those of glutathione increased [65].

\subsubsection{Modulation of Drug Metabolizing Enzymes}

The correct functioning of drug metabolism is essential in transforming and removing foreign substances from the organism. The expression and functions of the enzymes taking part in this process can be altered in some physiological situations [84], and the enhancement of their capacity could protect against pathologies, such as cancer [85]. Therefore, the effect of phenolic compounds on drug metabolizing enzymes has been previously evaluated.

In a study from Miene et al., the expression of two drug metabolizing enzymes, namely glutathione S-transferase theta-2 (GSTT2) and COX-2, in LT97 human colon cells was modulated by 3,4-DHPA and 3,4-DHPP [66]. Microbial metabolites both increased the GSTT2 mRNA expression up to 1.7-fold $(2.5$ and $5 \mu \mathrm{M})$. On the contrary, COX-2 mRNA was reduced after the incubation with both microbial metabolites [66]. COX-2 protein expression was dose-dependently reduced after treatment with 3,4-DHPA $(5-10 \mu \mathrm{M})$ and 3,4-DHPP $(15-25 \mu \mathrm{M})$ during $48 \mathrm{~h}$, but no effect was seen after $24 \mathrm{~h}$ incubation [66].

3,4-DHPA also modulated the gene expression of drug metabolizing enzymes as well in Hepa1c1c7 cells in a study from Tang et al. [49]. The mRNA levels of glutamate-cysteine ligase catalytic subunit (GCLC), heme oxygenase 1 (HO-1), and NADH: quinone oxidoreductase-1 (NQO1) significantly increased at concentrations of the metabolite of 5, 10, and $25 \mu \mathrm{M}$, respectively [49]. The mRNA levels of cystine/glutamate anti-porter (xCT) and Cytochrome P450 1A1 (CYP1A1) were additionally increased, but at higher concentrations of 100 and $250 \mu \mathrm{M}$, respectively [49]. The GSH-activity in RL34 normal hepatocytes was also increased in a dose-dependent manner, and reached an activity of 1.4-fold higher than control levels [49]. Moreover, 3,4-DHPA reduced the cytotoxic effect of peroxide in Hepa1c1c7 cells in a concentration-dependent manner, and cell viability was completely restored to control levels at a concentration of $100 \mu \mathrm{M}$ [49].

Furthermore, Xue et al. reported that 3,4-DHPA was able to inhibit oxidative stress in acetaminophen-induced hepatotoxicity in rats by decreasing malondialdehyde levels and by dose-dependently increasing the antioxidant enzymes glutathione (GSH), glutathione peroxidase (GPx), glutathione S-transferase (GST), and superoxide dismutase (SOD) to prevent the decrease of UDP-glucuronosyltransferase (UGT) and sulfotransferase (SULT)'s activity induced by acetaminophen [67].

The effect of 3,4-DHPA on aldehyde dehydrogenase was also investigated by Liu et al., and the authors found that, after treatment of mouse hepatoma Hepa1c1c7 cells, the total activity of ALDH increased, as well as the expression of ADLH1A1, ADLH2 and ALDH3A1 [68]. The authors also showed that 3,4-DHPA activates the signalling pathways of Nrf2 and AhR to possibly increase the expression of the ALDH genes, but inhibits that of NF- $\mathrm{kB}$ [68].

In addition to 3,4-DHPA, protocatechuic acid was also shown to modulate drug metabolizing enzymes. Ibitoye et al. administered protocatechuic acid to rats at 10 and $20 \mathrm{mg} / \mathrm{kg}$ and it significantly reversed menadione-induced increases in superoxide ions and hydrogen peroxide in addition to decreases in the activities of SOD and catalase (CAT) [69]. The metabolite reversed the induced decrease in GST and NQO-1, and significantly increased Nrf-2, Akt, and PI3K, which suggests that this is a possible pathway for the increasing antioxidant and phase II metabolizing activities [69]. 


\subsubsection{Modulation of Intestinal Microbiota}

Ma et al. investigated the effect of one microbial metabolite, ferulic acid, on faecal microbiota of HFD-induced obese mice [70]. The authors reported that FA significantly reduced the ratio of Firmicutes to Bacteroidetes when compared to the obese control group [70].

The growth of two probiotic (Lactobacillus rhamnosus and L. acidophilus) and two pathogenic bacteria (Escherichia coli and Salmonella enterica serovar Typhimurium) in the presence of gallic acid, vanillic acid, ferulic acid, and protocatechuic acid was evaluated in another study [71]. The results showed that the minimal inhibitory concentration (MIC) and minimal bactericidal concentration (MBC) of phenolic acids against $E$. coli and $S$. Typhimurium showed similar values of $15-30 \mathrm{mmol} / \mathrm{L}$ [71]. However, the MICs were higher for probiotics (mostly $>35 \mathrm{mmol} / \mathrm{L}$ ), except in the case of ferulic acid (MIC $=20 \mathrm{mmol} / \mathrm{L}$ ) [71]. The MBC were, in this case, higher than $35 \mathrm{mmol} / \mathrm{L}$ for all metabolites. Furthermore, the presence of the metabolites in MRS broth without dextrose promoted the growth of lactobacilli [71]. Therefore, the compounds selectively inhibited the growth of pathogenic bacteria without affecting the viability of probiotics [71].

\subsubsection{Modulation of Lipid Metabolism}

The effect of ferulic acid on lipid metabolism in high-fat diet-induced obese mice was studied by Naowaboot et al. [72]. The results show that this metabolite at a dosage of 25 and $50 \mathrm{mg} / \mathrm{kg}$ reduced the serum lipid level (total cholesterol, triglycerides, and non-esterified fatty acids), as well as liver cholesterol and triglyceride when compared to the obese mice control group [72]. This could be explained by the modulation of the lipogenic genes: the expression of sterol regulatory element-binding protein 1c (SREBP1c), fatty acid synthase (FAS), and acetyl-CoA carboxylase (ACC) were reduced by the metabolite [72]. Moreover, hepatic carnitine palmitoyltransferase 1a (CPT1a) gene and peroxisome proliferator-activated receptor alpha (PPAR $\alpha)$ proteins were up-regulated, being involved in the stimulation of $\beta$-oxidation genes [72].

Similarly, after a 12-week treatment of high-fat diet-induced obese mice with $30 \mathrm{mg} / \mathrm{kg}$ of ferulic acid, serum total cholesterol, triglycerides, and LDL cholesterol significantly decreased when compared to obese control group [70]. Total cholesterol and triglyceride levels in liver were as well significantly reduced after treatment with the metabolite [70]. The mechanism could be due to the significant increase of aryl hydrocarbon receptor (AHR)'s mRNA expression, which is thought to regulate lipid metabolism and inhibit FAS and SREBP1c. Indeed, after treatment with ferulic acid the mRNA expression of FAS and SREBP-1c decreased [70].

\subsubsection{Neuroprotective Effect}

Through their antioxidant, anti-inflammatory and anti-apoptotic properties, low molecular phenolics could also exert a protective effect against neuronal diseases. In a study from Verzelloni et al., the prevention of cytotoxicity induced by 2,3-dimethoxy-1,4-naphtoquinone (DMNQ) was tested on human neuroblastoma SK-N-MC cells after treatment with pyrogallol, 3,4-DHPP, dihydroferulic acid, 3-hydroxyphenylacetic acid (3-HPA), 3,4-DHPA or homovanillic acid [39]. Although all of the metabolites had a positive impact on the survival of human neuroblastoma cells, only 3-HPA did it in a concentration-dependent manner. Dihydroferulic acid at $20 \mu \mathrm{mol} / \mathrm{L}$ induced the greatest increase in cell survival $(17.07 \pm 4.2 \%$ at $20 \mu \mathrm{mol} / \mathrm{L})$, followed by pyrogallol $(12.0 \pm 2.5 \%$ at $20 \mu \mathrm{mol} / \mathrm{L})$ and 3,4-DHPA (11.0 \pm 0.6 and $11.0 \pm 2.2 \%$ at 10 and $20 \mu \mathrm{mol} / \mathrm{L}$, respectively). Different combinations of metabolites at a final concentration of $1.5 \mu \mathrm{mol} / \mathrm{L}$ also exerted significant protection on neuroblastoma cells [39].

In a model of neuroinflammation, SH-SY5Y human neuroblastoma cells were exposed to SIN-1-induced nitrosative stress and treated with 3,4-DHPA, 3-HPP, and 3-HPA [74]. All metabolites at concentrations between $0.1-10 \mu \mathrm{M}$ enhanced cell viability when compared to control group, but 3,4-DHPA had the strongest effect at $10 \mu \mathrm{M}$ not only after short time exposure, but also after more 
prolonged time exposure to SIN-1 [74]. The increase in caspase-3 activation induced by SIN-1 was also reduced when the SH-SY5Y cells were treated with $10 \mu \mathrm{M}$ 3-HPP [74]. Possible mechanisms are the reduction of SIN-1-induced increase of p38 phosphorylation by 3-HPA and of ERK1/2 phosphorylation by all metabolites [74].

The same cell line was exposed to $\mathrm{H}_{2} \mathrm{O}_{2}$ in a study from González-Sarrías et al. and treated with 3,4-DHPP, 3,4-DHPA, and gallic acid, among other polyphenol-derived metabolites [75]. The negative effects of $\mathrm{H}_{2} \mathrm{O}_{2}$ on SH-SY5Y neuroblastoma cell viability were reverted and the percentage of late apoptosis decreased up to approximately $12 \%$ with $10 \mu \mathrm{M}$ pretreatment or cotreatment with the metabolites as compared with $\mathrm{H}_{2} \mathrm{O}_{2}$ treatment alone [75].

In primary cultures of cerebellar granule neurons, 4-hydroxybenzoic acid (100 and $200 \mu \mathrm{M})$ and protocatechuic acid (50-200 $\mu \mathrm{M}$ ) protected cells from oxidative stress induced by $\mathrm{H}_{2} \mathrm{O}_{2}$ [76]. Under conditions of nitrosative stress typical from inflammative situations in the central nervous system, only protocatechuic acid $(10-300 \mu \mathrm{M})$ was neuroprotective [76]. However, under conditions of excitotoxicity only 4-hydroxybenzoic acid prevented neuronal death [76]. The ability of these metabolites to alter NO production in a BV2 microglial cell line following treatment with LPS was also tested, and only protocatechuic acid at $100 \mu \mathrm{M}$ exerted anti-inflammatory activity reducing NO production [76].

In a lysolecithin (LPC)-induced model of inflammation in hippocampal neurons, gallic acid and valeric acid, at 1 and $0.2 \mu \mathrm{M}$, respectively, inhibited the LPC-induced demyelination and promoted the formation of myelin, as well as neurite outgrowth [78].

In vivo, the progress of hippocampal neurodegeneration in the brain of diabetic rats was reduced after the administration of 20 and $40 \mathrm{mg} / \mathrm{kg}$ gallic acid and $p$-coumaric acid, respectively [73]. These metabolites exerted antioxidant, anti-inflammatory, and anti-apoptotic activities, which probably mediated the protective effects on the hippocampus [73].

Kho et al. recently also evaluated in vivo the effects of protocatechuic acid at a dose of $30 \mathrm{mg} / \mathrm{kg}$ on global cerebral ischemia-induced hippocampal neuronal death in rats [77]. The protocatechuic acid-treated rats showed $51 \%, 58 \%, 75 \%$, and $76 \%$ fewer degenerating neurons than in the vehicle-treated group in the hippocampal areas cornu ammonis 1, subiculum, cornu ammonis 3 , and dentate gyrus, respectively [77]. Additionally, ischemia-induced blood-brain barrier disruption was prevented and the induced inflammatory responses mediated by microglia and astrocytes. Oxidative injury was reduced by the metabolite, and the GSH levels after the treatment increased 37\% [77].

\subsubsection{Osteoprotective Effect}

Some low molecular weight phenolics could be effective in preventing bone resorption. In particular, protocatechuic acid was able to inhibit osteoclastogenesis and bone loss in in vivo and in vitro models in a study from Park et al. [79]. At concentrations between 1 and $25 \mu \mathrm{M}$, protocatechuic acid dose-dependently inhibited RANKL-induced osteoclast differentiation in mouse bone marrow macrophages and blocked the bone-resorbing activity of mature osteoclasts, probably by suppressing JNK signaling, c-Fos stability, and the expression of osteoclastic marker genes [79]. Mice that were treated with protocatechuic acid efficiently recovered from LPS-induced bone loss in vivo [79].

In another study from $\mathrm{Wu}$ et al., protocatechuic acid was also shown to suppress osteoclast differentiation and induce apoptosis in mature osteoclasts [80]. It dose-dependently reduced the Tartrate-resistance acid phosphatase (TRAP) activity induced by RANKL and multinucleated osteoclast formation at a concentration up to $10 \mu \mathrm{M}$, as well as ROS and lipid peroxide levels with an increase in antioxidant status [80]. Osteoclast specific markers and transcription factors' expression was significantly downregulated when compared to that of RANKL, as well as MAPK activation and the expression of inflammatory proteins [80]. Oxidative stress and inflammation were shown to be regulated by protocatechuic acid through regulating the transcription factor Nrf-2 [80]. Moreover, in mature osteoclasts it induced apoptosis by the loss of mitochondrial membrane potential, cytochrome c release, and caspase activation [80]. 


\subsubsection{Renoprotective Effects}

Several studies tried to define the preventive properties of microbial phenolic metabolites on diabetic nephropathy, which is a common complication in diabetic patients. In a recent study from Álvarez-Cilleros et al., the renal proximal tubular NRK-52E cells were treated under high glucose levels with 3,4-DHPA in order to assess its protective effect on the redox status [81]. 3,4-DHPA at $10 \mu \mathrm{M}$ reversed the glucose-induced ROS production and the decrease of antioxidant defenses [81]. SIRT-1 and NADPH-oxidase-4 (NOX-4) appear to play a key role in 3,4-DHPA-mediated renal protection [81].

Protocatechuic acid could also have beneficial effects on renal disease, as shown by Ma et al. [82]. At concentrations between 5 and $10 \mu \mathrm{M}$, it dose-dependently inhibited the high glucose-induced proliferation of human mesangial cells and suppressed extracellular matrix expression (type IV collagen, laminin, and fibronectin) [82]. Similarly, the levels of ROS and malondialdehyde induced by high glucose were decreased [82]. The mechanistic proposed by the authors is related to the p38 mitogen-activated protein kinase (MAPK) signaling pathway, since protocatechuic acid downregulated their phosphorylation levels in high glucose-stimulated mesangial cells [82].

\section{Predictive Potential}

In addition to the fact that they are highly bioavailable, when studying the biological activities of flavan-3-ol microbial catabolites, it is important to consider their physiological concentration in plasma after their absorption. Many of the bioactivity studies performed used metabolite concentrations that were much higher than the ones reported in plasma [15-20], therefore making the results difficult to relate to health effects in humans.

However, it is worth mentioning that microbial low molecular weight phenolics, in contrast to phenyl- $\gamma$-valerolactones, can be formed not only from flavan-3-ols, but also after colonic degradation of many other polyphenols present in food. Therefore, they can be formed from different sources and absorbed in the colon in a continuous manner, which could suggest a higher plasma concentration in the actual physiological conditions.

Interestingly, Uhlenhut and Högger reported a high binding capacity of a phenyl- $\gamma$-valerolactone to macrophages, monocytes, and endothelial cell, which made the authors suggest this intracellular accumulation to be the reason why in vivo bioactivity appears at plasma concentrations that exert no effect in vitro [22].

Some authors assessed the effects of mixtures of metabolites [26,39,42,58,61,62,64,71], and reported that some of these combinations had greater activities than the individual compounds. This is also important to consider a more realistic approach, since a huge variety of microbial metabolites are formed in the colon from flavan-3-ols and from other polyphenols, and are therefore present in the organism together and not isolated.

Furthermore, the bioactivity of not only the microbial metabolites, but also of their conjugated forms has been examined in several studies $[21,28,42]$. This is of unquestionable relevance, since the microbial catabolites formed in the colon can be further conjugated, and these forms might also contribute to the biological actions of the flavan-3-ols too.

Although the flavan-3-ol colonic metabolic pathway has been almost fully elucidated and many of their microbial metabolites have been identified, their formation has been shown to differ among individuals, as reviewed elsewhere [4]. These interindividual differences in the formation of microbial metabolites can be explained by differences in gut microbiota composition, and this is commonly termed in the literature as "metabotype". Since several biological properties have been associated with flavan-3-ol microbial metabolites, specific metabotypes producing these catabolites could be predictors of their health effects, as previously shown for other polyphenols [86-88].

While metabotypes for determined microbial metabolites from polyphenols, such as ellagitannins [89] and isoflavones [90], have been well studied and described, less is known about the gut metabolic phenotypes that are involved in the production of flavan-3-ol colonic metabolites. 
Three metabotypes in the formation of flavan-3-ol microbial metabolites were recently proposed for the first time in a study by Mena et al. $(n=11)$. These were defined by the different production amounts of trihydroxyphenyl- $\gamma$-valerolactones, dihydroxyphenyl- $\gamma$-valerolactones, and hydroxyphenylpropionic acid [91]. In contrast, another study showed that there were no specific proanthocyanidin-derived microbial metabolites that enabled the stratification of individuals by metabotypes, which suggests no influence of interindividual gut microbiota differences on the diverging health effects of proanthocyanidins [92]. Due to the high number of subjects needed for the identification of metabotypes and the difficulty of using phenyl- $\gamma$-valerolactones as determinant for metabotypes [93], more research is needed in this area.

\section{Conclusions}

There are numerous available studies that suggest positive effects of flavan-3-ol microbial metabolites. However, caution needs to be taken when interpreting their results and extrapolating them to humans, since only cellular and animal models have been performed. In this regard, human in vivo studies of microbial metabolites may not be realistic either, since their oral administration by human beings would not reproduce their actual formation through microbial metabolism in the colon. Moreover, other factors need to be considered when evaluating the positive health effects of microbial metabolites, such as individual differences in their colonic production, bioavailability, and concentration in biological fluids and tissues.

Although the interest in microbial metabolites of flavan-3-ols has been growing over the last few years and many studies have been performed with the aim of understanding their biological effects in organisms, further research that clarifies their metabotype-dependent formation, their conjugation, and their pharmacokinetics patterns are needed in an attempt to harmonize the study methodologies and, ultimately, to elucidate their health benefits in human beings.

Author Contributions: E.M.C. and M.-C.S. wrote the paper; M.-C.S. and P.S. conceived and supervised the project.

Funding: This work was funded by the Department of Nutrition and Food Sciences, Nutritional Physiology, University of Bonn and supported by the grant no 01EA1372D of the German Federal Ministry of Education and Research.

Acknowledgments: The authors would like to thank Katherine Macmillan for the professional English editing service.

Conflicts of Interest: The authors declare no conflict of interest.

\section{References}

1. Vogiatzoglou, A.; Mulligan, A.A.; Lentjes, M.A.H.; Luben, R.N.; Spencer, J.P.E.; Schroeter, H.; Khaw, K.-T.; Kuhnle, G.G.C. Flavonoid Intake in European Adults (18 to 64 Years). PLoS ONE 2015, 10, e0128132. [CrossRef] [PubMed]

2. Karam, J.; Bibiloni, M.D.M.; Tur, J.A. Polyphenol estimated intake and dietary sources among older adults from Mallorca Island. PLoS ONE 2018, 13, e0191573. [CrossRef] [PubMed]

3. Monagas, M.; Urpi-Sarda, M.; Sánchez-Patán, F.; Llorach, R.; Garrido, I.; Gómez-Cordovés, C.; Andres-Lacueva, C.; Bartolomé, B. Insights into the metabolism and microbial biotransformation of dietary flavan-3-ols and the bioactivity of their metabolites. Food Funct. 2010, 1, 233-253. [CrossRef] [PubMed]

4. Mena, P.; Bresciani, L.; Brindani, N.; Ludwig, I.A.; Pereira-Caro, G.; Angelino, D.; Llorach, R.; Calani, L.; Brighenti, F.; Clifford, M.N.; et al. Phenyl- $\gamma$-valerolactones and phenylvaleric acids, the main colonic metabolites of flavan-3-ols: Synthesis, analysis, bioavailability, and bioactivity. Nat. Prod. Rep. 2019, 36, 714-752. [CrossRef] [PubMed]

5. Del Rio, D.; Rodríguez-Mateos, A.; Spencer, J.P.E.; Tognolini, M.; Borges, G.; Crozier, A. Dietary (poly)phenolics in human health: Structures, bioavailability, and evidence of protective effects against chronic diseases. Antioxid. Redox Signal. 2013, 18, 1818-1892. [CrossRef] [PubMed]

6. Manach, C.; Scalbert, A.; Morand, C.; Rémésy, C.; Jiménez, L. Polyphenols: Food sources and bioavailability. Am. J. Clin. Nutr. 2004, 79, 727-747. [CrossRef] [PubMed] 
7. Kuhnle, G.G.C. Nutrition epidemiology of flavan-3-ols: The known unknowns. Mol. Asp. Med. 2018, 61, 2-11. [CrossRef]

8. Raman, G.; Shams-White, M.; Avendano, E.E.; Chen, F.; Novotny, J.A.; Cassidy, A. Dietary intakes of flavan-3-ols and cardiovascular health: A field synopsis using evidence mapping of randomized trials and prospective cohort studies. Syst. Rev. 2018, 7, 100. [CrossRef]

9. Lei, L.; Yang, Y.; He, H.; Chen, E.; Du, L.; Dong, J.; Yang, J. Flavan-3-ols consumption and cancer risk: A meta-analysis of epidemiologic studies. Oncotarget 2016, 7, 73573-73592. [CrossRef]

10. Del Rio, D.; Calani, L.; Cordero, C.; Salvatore, S.; Pellegrini, N.; Brighenti, F. Bioavailability and catabolism of green tea flavan-3-ols in humans. Nutrition 2010, 26, 1110-1116. [CrossRef]

11. Olthof, M.R.; Hollman, P.C.H.; Buijsman, M.N.C.P.; van Amelsvoort, J.M.M.; Katan, M.B. Chlorogenic Acid, Quercetin-3-Rutinoside and Black Tea Phenols Are Extensively Metabolized in Humans. J. Nutr. 2003, 133, 1806-1814. [CrossRef] [PubMed]

12. De Ferrars, R.M.; Czank, C.; Zhang, Q.; Botting, N.P.; Kroon, P.A.; Cassidy, A.; Kay, C.D. The pharmacokinetics of anthocyanins and their metabolites in humans. Br. J. Pharmacol. 2014, 171, 3268-3282. [CrossRef] [PubMed]

13. Li, C.; Lee, M.J.; Sheng, S.; Meng, X.; Prabhu, S.; Winnik, B.; Huang, B.; Chung, J.Y.; Yan, S.; Ho, C.T.; et al. Structural identification of two metabolites of catechins and their kinetics in human urine and blood after tea ingestion. Chem. Res. Toxicol. 2000, 13, 177-184. [CrossRef] [PubMed]

14. Roowi, S.; Stalmach, A.; Mullen, W.; Lean, M.E.J.; Edwards, C.A.; Crozier, A. Green tea flavan-3-ols: Colonic degradation and urinary excretion of catabolites by humans. J. Agric. Food Chem. 2010, 58, 1296-1304. [CrossRef] [PubMed]

15. Ottaviani, J.I.; Borges, G.; Momma, T.Y.; Spencer, J.P.E.; Keen, C.L.; Crozier, A.; Schroeter, H. The metabolome of [2-(14) C] (-)-epicatechin in humans: Implications for the assessment of efficacy, safety, and mechanisms of action of polyphenolic bioactives. Sci. Rep. 2016, 6, 29034. [CrossRef] [PubMed]

16. Urpi-Sarda, M.; Monagas, M.; Khan, N.; Llorach, R.; Lamuela-Raventós, R.M.; Jáuregui, O.; Estruch, R.; Izquierdo-Pulido, M.; Andrés-Lacueva, C. Targeted metabolic profiling of phenolics in urine and plasma after regular consumption of cocoa by liquid chromatography-tandem mass spectrometry. J. Chromatogr. A 2009, 1216, 7258-7267. [CrossRef] [PubMed]

17. Wiese, S.; Esatbeyoglu, T.; Winterhalter, P.; Kruse, H.-P.; Winkler, S.; Bub, A.; Kulling, S.E. Comparative biokinetics and metabolism of pure monomeric, dimeric, and polymeric flavan-3-ols: A randomized cross-over study in humans. Mol. Nutr. Food Res. 2015, 59, 610-621. [CrossRef] [PubMed]

18. Rodriguez-Mateos, A.; Feliciano, R.P.; Boeres, A.; Weber, T.; Dos Santos, C.N.; Ventura, M.R.; Heiss, C. Cranberry (poly)phenol metabolites correlate with improvements in vascular function: A double-blind, randomized, controlled, dose-response, crossover study. Mol. Nutr. Food Res. 2016, 60, 2130-2140. [CrossRef]

19. Castello, F.; Costabile, G.; Bresciani, L.; Tassotti, M.; Naviglio, D.; Luongo, D.; Ciciola, P.; Vitale, M.; Vetrani, C.; Galaverna, G.; et al. Bioavailability and pharmacokinetic profile of grape pomace phenolic compounds in humans. Arch. Biochem. Biophys. 2018, 646, 1-9. [CrossRef]

20. Feliciano, R.P.; Boeres, A.; Massacessi, L.; Istas, G.; Ventura, M.R.; Nunes dos Santos, C.; Heiss, C.; Rodriguez-Mateos, A. Identification and quantification of novel cranberry-derived plasma and urinary (poly)phenols. Arch. Biochem. Biophys. 2016, 599, 31-41. [CrossRef]

21. Mena, P.; González de Llano, D.; Brindani, N.; Esteban-Fernández, A.; Curti, C.; Moreno-Arribas, M.V.; Del Rio, D.; Bartolomé, B. 5-(3', 4' -Dihydroxyphenyl)- $\gamma$-valerolactone and its sulphate conjugates, representative circulating metabolites of flavan-3-ols, exhibit anti-adhesive activity against uropathogenic Escherichia coli in bladder epithelial cells. J. Funct. Foods 2017, 29, 275-280. [CrossRef]

22. Uhlenhut, K.; Högger, P. Facilitated cellular uptake and suppression of inducible nitric oxide synthase by a metabolite of maritime pine bark extract (Pycnogenol). Free Radic. Biol. Med. 2012, 53, 305-313. [CrossRef] [PubMed]

23. Takagaki, A.; Nanjo, F. Effects of Metabolites Produced from (-)-Epigallocatechin Gallate by Rat Intestinal Bacteria on Angiotensin I-Converting Enzyme Activity and Blood Pressure in Spontaneously Hypertensive Rats. J. Agric. Food Chem. 2015, 63, 8262-8266. [CrossRef] [PubMed]

24. Lee, C.C.; Kim, J.H.; Kim, J.S.; Oh, Y.S.; Han, S.M.; Park, J.H.Y.; Lee, K.W.; Lee, C.Y. 5-(3', 4' -Dihydroxyphenyl- $\gamma$-valerolactone), a Major Microbial Metabolite of Proanthocyanidin, Attenuates THP-1 Monocyte-Endothelial Adhesion. Int. J. Mol. Sci. 2017, 18, 1363. [CrossRef] [PubMed] 
25. Hara-Terawaki, A.; Takagaki, A.; Kobayashi, H.; Nanjo, F. Inhibitory Activity of Catechin Metabolites Produced by Intestinal Microbiota on Proliferation of HeLa Cells. Biol. Pharm. Bull. 2017, 40, 1331-1335. [CrossRef] [PubMed]

26. Stanisławska, I.J.; Granica, S.; Piwowarski, J.P.; Szawkało, J.; Wiązecki, K.; Czarnocki, Z.; Kiss, A.K. The Activity of Urolithin A and M4 Valerolactone, Colonic Microbiota Metabolites of Polyphenols, in a Prostate Cancer in Vitro Model. Planta Med. 2019, 85, 118-125. [CrossRef] [PubMed]

27. Kim, Y.H.; Won, Y.-S.; Yang, X.; Kumazoe, M.; Yamashita, S.; Hara, A.; Takagaki, A.; Goto, K.; Nanjo, F.; Tachibana, H. Green Tea Catechin Metabolites Exert Immunoregulatory Effects on CD4(+) T Cell and Natural Killer Cell Activities. J. Agric. Food Chem. 2016, 64, 3591-3597. [CrossRef] [PubMed]

28. Unno, K.; Pervin, M.; Nakagawa, A.; Iguchi, K.; Hara, A.; Takagaki, A.; Nanjo, F.; Minami, A.; Nakamura, Y. Blood-Brain Barrier Permeability of Green Tea Catechin Metabolites and their Neuritogenic Activity in Human Neuroblastoma SH-SY5Y Cells. Mol. Nutr. Food Res. 2017, 61, 1700294. [CrossRef] [PubMed]

29. Foxman, B. Urinary Tract Infection Syndromes: Occurrence, Recurrence, Bacteriology, Risk Factors, and Disease Burden. Infect. Dis. Clin. N. Am. 2014, 28, 1-13. [CrossRef] [PubMed]

30. Foo, L.Y.; Lu, Y.; Howell, A.B.; Vorsa, N. A-Type proanthocyanidin trimers from cranberry that inhibit adherence of uropathogenic P-fimbriated Escherichia coli. J. Nat. Prod. 2000, 63, 1225-1228. [CrossRef]

31. Howell, A.B.; Reed, J.D.; Krueger, C.G.; Winterbottom, R.; Cunningham, D.G.; Leahy, M. A-type cranberry proanthocyanidins and uropathogenic bacterial anti-adhesion activity. Phytochemistry 2005, 66, 2281-2291. [CrossRef] [PubMed]

32. De Llano, D.G.; Esteban-Fernández, A.; Sánchez-Patán, F.; Martínlvarez, P.J.; Moreno-Arribas, M.V.; Bartolomé, B. Anti-Adhesive Activity of Cranberry Phenolic Compounds and Their Microbial-Derived Metabolites against Uropathogenic Escherichia coli in Bladder Epithelial Cell Cultures. Int. J. Mol. Sci. 2015, 16, 12119-12130. [CrossRef] [PubMed]

33. Scazzocchio, B.; Varì, R.; Filesi, C.; D’Archivio, M.; Santangelo, C.; Giovannini, C.; Iacovelli, A.; Silecchia, G.; Li Volti, G.; Galvano, F.; et al. Cyanidin-3-O- $\beta$-glucoside and protocatechuic acid exert insulin-like effects by upregulating PPAR $\gamma$ activity in human omental adipocytes. Diabetes 2011, 60, 2234-2244. [CrossRef] [PubMed]

34. Fernández-Millán, E.; Ramos, S.; Alvarez, C.; Bravo, L.; Goya, L.; Martín, M.Á. Microbial phenolic metabolites improve glucose-stimulated insulin secretion and protect pancreatic beta cells against tert-butyl hydroperoxide-induced toxicity via ERKs and PKC pathways. Food Chem. Toxicol. 2014, 66, 245-253. [CrossRef]

35. Carrasco-Pozo, C.; Gotteland, M.; Castillo, R.L.; Chen, C. 3,4-Dihydroxyphenylacetic acid, a microbiota-derived metabolite of quercetin, protects against pancreatic $\beta$-cells dysfunction induced by high cholesterol. Exp. Cell Res. 2015, 334, 270-282. [CrossRef] [PubMed]

36. Álvarez-Cilleros, D.; Martín, M.Á.; Ramos, S. (-)-Epicatechin and the Colonic 2,3-Dihydroxybenzoic Acid Metabolite Regulate Glucose Uptake, Glucose Production, and Improve Insulin Signaling in Renal NRK-52E Cells. Mol. Nutr. Food Res. 2018, 62, 1700470. [CrossRef] [PubMed]

37. Álvarez-Cilleros, D.; Martín, M.Á.; Ramos, S. Protective effects of (-)-epicatechin and the colonic metabolite 3,4-dihydroxyphenylacetic acid against glucotoxicity-induced insulin signalling blockade and altered glucose uptake and production in renal tubular NRK-52E cells. Food Chem. Toxicol. 2018, 120, 119-128. [CrossRef] [PubMed]

38. Bitner, B.F.; Ray, J.D.; Kener, K.B.; Herring, J.A.; Tueller, J.A.; Johnson, D.K.; Tellez Freitas, C.M.; Fausnacht, D.W.; Allen, M.E.; Thomson, A.H.; et al. Common gut microbial metabolites of dietary flavonoids exert potent protective activities in $\beta$-cells and skeletal muscle cells. J. Nutr. Biochem. 2018, 62, 95-107. [CrossRef] [PubMed]

39. Verzelloni, E.; Pellacani, C.; Tagliazucchi, D.; Tagliaferri, S.; Calani, L.; Costa, L.G.; Brighenti, F.; Borges, G.; Crozier, A.; Conte, A.; et al. Antiglycative and neuroprotective activity of colon-derived polyphenol catabolites. Mol. Nutr. Food Res. 2011, 55 (Suppl 1), S35-S43. [CrossRef] [PubMed]

40. Giménez-Bastida, J.A.; Zielinski, H.; Piskula, M.; Zielinska, D.; Szawara-Nowak, D. Buckwheat bioactive compounds, their derived phenolic metabolites and their health benefits. Mol. Nutr. Food Res. 2017, 61, 1600475. [CrossRef]

41. Yang, X.-W.; Wang, N.; Li, W.; Xu, W.; Wu, S. Biotransformation of 4,5-O-dicaffeoylquinic acid methyl ester by human intestinal flora and evaluation on their inhibition of NO production and antioxidant activity of the products. Food Chem. Toxicol. 2013, 55, 297-303. [CrossRef] [PubMed] 
42. Di Gesso, J.L.; Kerr, J.S.; Zhang, Q.; Raheem, S.; Yalamanchili, S.K.; O’Hagan, D.; Kay, C.D.; O'Connell, M.A. Flavonoid metabolites reduce tumor necrosis factor- $\alpha$ secretion to a greater extent than their precursor compounds in human THP-1 monocytes. Mol. Nutr. Food Res. 2015, 59, 1143-1154. [CrossRef] [PubMed]

43. Wang, H.-Y.; Wang, H.; Wang, J.-H.; Wang, Q.; Ma, Q.-F.; Chen, Y.-Y. Protocatechuic Acid Inhibits Inflammatory Responses in LPS-Stimulated BV2 Microglia via NF-кB and MAPKs Signaling Pathways. Neurochem. Res. 2015, 40, 1655-1660. [CrossRef] [PubMed]

44. Wang, Y.; Zhou, J.; Fu, S.; Wang, C.; Zhou, B. Preventive Effects of Protocatechuic Acid on LPS-Induced Inflammatory Response in Human Gingival Fibroblasts via Activating PPAR- $\gamma$. Inflammation 2015, 38, 1080-1084. [CrossRef] [PubMed]

45. Crespo, I.; San-Miguel, B.; Mauriz, J.L.; Ortiz de Urbina, J.J.; Almar, M.; Tuñón, M.J.; González-Gallego, J. Protective Effect of Protocatechuic Acid on TNBS-Induced Colitis in Mice Is Associated with Modulation of the SphK/S1P Signaling Pathway. Nutrients 2017, 9, 288. [CrossRef] [PubMed]

46. Ho, G.T.T.; Wangensteen, H.; Barsett, H. Elderberry and Elderflower Extracts, Phenolic Compounds, and Metabolites and Their Effect on Complement, RAW 264.7 Macrophages and Dendritic Cells. Int. J. Mol. Sci. 2017, 18, 584. [CrossRef] [PubMed]

47. Zhu, L.; Gu, P.; Shen, H. Gallic acid improved inflammation via NF-кB pathway in TNBS-induced ulcerative colitis. Int. Immunopharmacol. 2019, 67, 129-137. [CrossRef]

48. Biskup, I.; Golonka, I.; Gamian, A.; Sroka, Z. Antioxidant activity of selected phenols estimated by ABTS and FRAP methods. Postep. Hig Med. Dosw (Online) 2013, 67, 958-963. [CrossRef]

49. Tang, Y.; Nakashima, S.; Saiki, S.; Myoi, Y.; Abe, N.; Kuwazuru, S.; Zhu, B.; Ashida, H.; Murata, Y.; Nakamura, Y. 3,4-Dihydroxyphenylacetic acid is a predominant biologically-active catabolite of quercetin glycosides. Food Res. Int. 2016, 89, 716-723. [CrossRef] [PubMed]

50. Rosa, L.D.S.; Jordão, N.A.; da Costa Pereira Soares, N.; deMesquita, J.F.; Monteiro, M.; Teodoro, A.J. Pharmacokinetic, Anti-proliferative and Apoptotic Effects of Phenolic Acids in Human Colon Adenocarcinoma Cells Using in Vitro and in Silico Approaches. Molecules 2018, 23, 2569. [CrossRef]

51. Varì, R.; Scazzocchio, B.; Santangelo, C.; Filesi, C.; Galvano, F.; D'Archivio, M.; Masella, R.; Giovannini, C. Protocatechuic Acid Prevents oxLDL-Induced Apoptosis by Activating JNK/Nrf2 Survival Signals in Macrophages. Oxid Med. Cell. Longev. 2015, 2015, 351827. [CrossRef] [PubMed]

52. Liu, Y.-D.; Sun, X.; Zhang, Y.; Wu, H.-J.; Wang, H.; Yang, R. Protocatechuic acid inhibits TGF- $\beta 1$-induced proliferation and migration of human airway smooth muscle cells. J. Pharmacol. Sci. 2019, 139, 9-14. [CrossRef] [PubMed]

53. Kim, K.; Bae, O.N.; Lim, K.M.; Noh, J.Y.; Kang, S.; Chung, K.Y.; Chung, J.H. Novel anti-platelet activity of protocatechuic acid through the inhibition of high shear stress-induced platelet aggregation. J. Pharmacol. Exp. Ther. 2012, 343, 704-711. [CrossRef] [PubMed]

54. Semaming, Y.; Kumfu, S.; Pannangpetch, P.; Chattipakorn, S.C.; Chattipakorn, N. Protocatechuic acid exerts a cardioprotective effect in type 1 diabetic rats. J. Endocrinol. 2014, 223, 13-23. [CrossRef] [PubMed]

55. Najmanová, I.; Pourová, J.; Vopršalová, M.; Pilařová, V.; Semecký, V.; Nováková, L.; Mladěnka, P. Flavonoid metabolite 3-(3-hydroxyphenyl) propionic acid formed by human microflora decreases arterial blood pressure in rats. Mol. Nutr. Food Res. 2016, 60, 981-991. [CrossRef]

56. Bhattacharjee, N.; Dua, T.K.; Khanra, R.; Joardar, S.; Nandy, A.; Saha, A.; De Feo, V.; Dewanjee, S. Protocatechuic Acid, a Phenolic from Sansevieria roxburghiana Leaves, Suppresses Diabetic Cardiomyopathy via Stimulating Glucose Metabolism, Ameliorating Oxidative Stress, and Inhibiting Inflammation. Front. Pharmacol. 2017, 8, 251. [CrossRef] [PubMed]

57. Qian, Y.; Babu, P.V.A.; Symons, J.D.; Jalili, T. Metabolites of flavonoid compounds preserve indices of endothelial cell nitric oxide bioavailability under glucotoxic conditions. Nutr. Diabetes 2017, 7, e286. [CrossRef]

58. Álvarez-Cilleros, D.; Ramos, S.; Goya, L.; Martín, M.Á. Colonic metabolites from flavanols stimulate nitric oxide production in human endothelial cells and protect against oxidative stress-induced toxicity and endothelial dysfunction. Food Chem. Toxicol. 2018, 115, 88-97. [CrossRef]

59. Pourová, J.; Najmanová, I.; Vopršalová, M.; Migkos, T.; Pilařová, V.; Applová, L.; Nováková, L.; Mladěnka, P. Two flavonoid metabolites, 3,4-dihydroxyphenylacetic acid and 4-methylcatechol, relax arteries ex vivo and decrease blood pressure in vivo. Vasc. Pharmacol. 2018, 111, 36-43. [CrossRef] 
60. Applová, L.; Karlíčková, J.; Warncke, P.; Macáková, K.; Hrubša, M.; Macháček, M.; Tvrdý, V.; Fischer, D.; Mladěnka, P. 4-Methylcatechol, a Flavonoid Metabolite with Potent Anti-platelet Effects. Mol. Nutr. Food Res. 2019, e1900261. [CrossRef]

61. Henning, S.M.; Wang, P.; Abgaryan, N.; Vicinanza, R.; de Oliveira, D.M.; Zhang, Y.; Lee, R.-P.; Carpenter, C.L.; Aronson, W.J.; Heber, D. Phenolic acid concentrations in plasma and urine from men consuming green or black tea and potential chemopreventive properties for colon cancer. Mol. Nutr. Food Res. 2013, 57, 483-493. [CrossRef]

62. López de Las Hazas, M.-C.; Mosele, J.I.; Macià, A.; Ludwig, I.A.; Motilva, M.-J. Exploring the Colonic Metabolism of Grape and Strawberry Anthocyanins and Their in Vitro Apoptotic Effects in HT-29 Colon Cancer Cells. J. Agric. Food Chem. 2017, 65, 6477-6487. [CrossRef] [PubMed]

63. Hu, J.; Lin, S.; Huang, J.J.; Cheung, P.C.K. Mechanistic Study of the in Vitro and in Vivo Inhibitory Effects of Protocatechuic Acid and Syringic Acid on VEGF-Induced Angiogenesis. J. Agric. Food Chem. 2018, 66, 6742-6751. [CrossRef] [PubMed]

64. Sadeghi Ekbatan, S.; Li, X.-Q.; Ghorbani, M.; Azadi, B.; Kubow, S. Chlorogenic Acid and Its Microbial Metabolites Exert Anti-Proliferative Effects, S-Phase Cell-Cycle Arrest and Apoptosis in Human Colon Cancer Caco-2 Cells. Int. J. Mol. Sci. 2018, 19, 723.

65. Xie, Z.; Guo, Z.; Wang, Y.; Lei, J.; Yu, J. Protocatechuic acid inhibits the growth of ovarian cancer cells by inducing apoptosis and autophagy. Phytother. Res 2018, 32, 2256-2263. [CrossRef]

66. Miene, C.; Weise, A.; Glei, M. Impact of polyphenol metabolites produced by colonic microbiota on expression of COX-2 and GSTT2 in human colon cells (LT97). Nutr. Cancer 2011, 63, 653-662. [CrossRef] [PubMed]

67. Xue, H.; Xie, W.; Jiang, Z.; Wang, M.; Wang, J.; Zhao, H.; Zhang, X. 3,4-Dihydroxyphenylacetic acid, a microbiota-derived metabolite of quercetin, attenuates acetaminophen (APAP)-induced liver injury through activation of Nrf-2. Xenobiotica 2016, 46, 931-939. [CrossRef] [PubMed]

68. Liu, Y.; Kurita, A.; Nakashima, S.; Zhu, B.; Munemasa, S.; Nakamura, T.; Murata, Y.; Nakamura, Y. 3,4-Dihydroxyphenylacetic acid is a potential aldehyde dehydrogenase inducer in murine hepatoma Hepa1c1c7 cells. Biosci. Biotechnol. Biochem. 2017, 81, 1978-1983. [CrossRef] [PubMed]

69. Ibitoye, O.B.; Ajiboye, T.O. Protocatechuic acid protects against menadione-induced liver damage by up-regulating nuclear erythroid-related factor 2. Drug Chem. Toxicol. 2018, 1-7. [CrossRef] [PubMed]

70. Ma, Y.; Chen, K.; Lv, L.; Wu, S.; Guo, Z. Ferulic acid ameliorates nonalcoholic fatty liver disease and modulates the gut microbiota composition in high-fat diet fed ApoE-/-mice. Biomed. Pharmacother. 2019, 113, 108753. [CrossRef] [PubMed]

71. Pacheco-Ordaz, R.; Wall-Medrano, A.; Goñi, M.G.; Ramos-Clamont-Montfort, G.; Ayala-Zavala, J.F.; González-Aguilar, G.A. Effect of phenolic compounds on the growth of selected probiotic and pathogenic bacteria. Lett. Appl. Microbiol. 2018, 66, 25-31. [CrossRef] [PubMed]

72. Naowaboot, J.; Piyabhan, P.; Munkong, N.; Parklak, W.; Pannangpetch, P. Ferulic acid improves lipid and glucose homeostasis in high-fat diet-induced obese mice. Clin. Exp. Pharmacol. Physiol. 2016, 43, 242-250. [CrossRef] [PubMed]

73. Abdel-Moneim, A.; Yousef, A.I.; Abd El-Twab, S.M.; Abdel Reheim, E.S.; Ashour, M.B. Gallic acid and p-coumaric acid attenuate type 2 diabetes-induced neurodegeneration in rats. Metab. Brain Dis. 2017, 32, 1279-1286. [CrossRef] [PubMed]

74. Esteban-Fernández, A.; Rendeiro, C.; Spencer, J.P.E.; Del Coso, D.G.; de Llano, M.D.G.; Bartolomé, B.; Moreno-Arribas, M.V. Neuroprotective Effects of Selected Microbial-Derived Phenolic Metabolites and Aroma Compounds from Wine in Human SH-SY5Y Neuroblastoma Cells and Their Putative Mechanisms of Action. Front. Nutr. 2017, 4, 3. [CrossRef] [PubMed]

75. González-Sarrías, A.; Núñez-Sánchez, M.Á.; Tomás-Barberán, F.A.; Espín, J.C. Neuroprotective Effects of Bioavailable Polyphenol-Derived Metabolites against Oxidative Stress-Induced Cytotoxicity in Human Neuroblastoma SH-SY5Y Cells. J. Agric. Food Chem. 2017, 65, 752-758. [CrossRef] [PubMed]

76. Winter, A.N.; Brenner, M.C.; Punessen, N.; Snodgrass, M.; Byars, C.; Arora, Y.; Linseman, D.A. Comparison of the Neuroprotective and Anti-Inflammatory Effects of the Anthocyanin Metabolites, Protocatechuic Acid and 4-Hydroxybenzoic Acid. Oxid. Med. Cell. Longev. 2017, 2017, 6297080. [CrossRef] [PubMed]

77. Kho, A.R.; Choi, B.Y.; Lee, S.H.; Hong, D.K.; Lee, S.H.; Jeong, J.H.; Park, K.-H.; Song, H.K.; Choi, H.C.; Suh, S.W. Effects of Protocatechuic Acid (PCA) on Global Cerebral Ischemia-Induced Hippocampal Neuronal Death. Int. J. Mol. Sci. 2018, 19, 1420. [CrossRef] 
78. Siddiqui, S.; Kamal, A.; Khan, F.; Jamali, K.S.; Saify, Z.S. Gallic and vanillic acid suppress inflammation and promote myelination in an in vitro mouse model of neurodegeneration. Mol. Biol. Rep. 2018, 46, 997-1011. [CrossRef] [PubMed]

79. Park, S.-H.; Kim, J.-Y.; Cheon, Y.-H.; Baek, J.M.; Ahn, S.-J.; Yoon, K.-H.; Lee, M.S.; Oh, J. Protocatechuic Acid Attenuates Osteoclastogenesis by Downregulating JNK/c-Fos/NFATc1 Signaling and Prevents Inflammatory Bone Loss in Mice. Phytother. Res. 2016, 30, 604-612. [CrossRef] [PubMed]

80. Wu, Y.-X.; Wu, T.-Y.; Xu, B.-B.; Xu, X.-Y.; Chen, H.-G.; Li, X.-Y.; Wang, G. Protocatechuic acid inhibits osteoclast differentiation and stimulates apoptosis in mature osteoclasts. Biomed. Pharmacother. 2016, 82, 399-405. [CrossRef] [PubMed]

81. Álvarez-Cilleros, D.; Martín, M.Á.; Goya, L.; Ramos, S. (-)-Epicatechin and the colonic metabolite 3,4-dihydroxyphenylacetic acid protect renal proximal tubular cell against high glucose-induced oxidative stress by modulating NOX-4/SIRT-1 signalling. J. Funct. Foods 2018, 46, 19-28. [CrossRef]

82. Ma, Y.; Chen, F.; Yang, S.; Chen, B.; Shi, J. Protocatechuic acid ameliorates high glucose-induced extracellular matrix accumulation in diabetic nephropathy. Biomed. Pharmacother. 2018, 98, 18-22. [PubMed]

83. Singh, R.; Barden, A.; Mori, T.; Beilin, L. Advanced glycation end-products: A review. Diabetologia 2001, 44, 129-146. [CrossRef] [PubMed]

84. Almazroo, O.A.; Miah, M.K.; Venkataramanan, R. Drug Metabolism in the Liver. Clin. Liver Dis. 2017, 21, 1-20. [PubMed]

85. Nakamura, Y.; Miyoshi, N. Electrophiles in Foods: The Current Status of Isothiocyanates and Their Chemical Biology. Biosci. Biotechnol. Biochem. 2010, 74, 242-255. [CrossRef] [PubMed]

86. Hazim, S.; Curtis, P.J.; Schär, M.Y.; Ostertag, L.M.; Kay, C.D.; Minihane, A.-M.; Cassidy, A. Acute benefits of the microbial-derived isoflavone metabolite equol on arterial stiffness in men prospectively recruited according to equol producer phenotype: A double-blind randomized controlled trial. Am. J. Clin. Nutr. 2016, 103, 694-702. [PubMed]

87. Frankenfeld, C.L. Cardiometabolic risk and gut microbial phytoestrogen metabolite phenotypes. Mol. Nutr. Food Res. 2017, 61, 1500900. [CrossRef] [PubMed]

88. González-Sarrías, A.; García-Villalba, R.; Romo-Vaquero, M.; Alasalvar, C.; Örem, A.; Zafrilla, P.; Tomás-Barberán, F.A.; Selma, M.V.; Espín, J.C. Clustering according to urolithin metabotype explains the interindividual variability in the improvement of cardiovascular risk biomarkers in overweight-obese individuals consuming pomegranate: A randomized clinical trial. Mol. Nutr. Food Res. 2017, 61, 1600830. [CrossRef] [PubMed]

89. Tomás-Barberán, F.A.; García-Villalba, R.; González-Sarrías, A.; Selma, M.V.; Espín, J.C. Ellagic Acid Metabolism by Human Gut Microbiota: Consistent Observation of Three Urolithin Phenotypes in Intervention Trials, Independent of Food Source, Age, and Health Status. J. Agric. Food Chem. 2014, 62, 6535-6538. [CrossRef] [PubMed]

90. Rowland, I.R.; Wiseman, H.; Sanders, T.A.B.; Adlercreutz, H.; Bowey, E.A. Interindividual Variation in Metabolism of Soy Isoflavones and Lignans: Influence of Habitual Diet on Equol Production by the Gut Microflora. Nutr. Cancer 2000, 36, 27-32. [CrossRef] [PubMed]

91. Mena, P.; Ludwig, I.A.; Tomatis, V.B.; Acharjee, A.; Calani, L.; Rosi, A.; Brighenti, F.; Ray, S.; Griffin, J.L.; Bluck, L.J.; et al. Inter-individual variability in the production of flavan-3-ol colonic metabolites: Preliminary elucidation of urinary metabotypes. Eur. J. Nutr. 2019, 58, 1529-1543. [CrossRef] [PubMed]

92. Cortés-Martín, A.; Selma, M.V.; Espín, J.C.; García-Villalba, R. The human metabolism of nuts proanthocyanidins does not reveal urinary metabolites consistent with distinctive gut microbiota metabotypes. Mol. Nutr. Food Res. 2019, 63, e1800819. [CrossRef] [PubMed]

93. Tomás-Barberán, F.A.; Espín, J.C. Effect of food structure and processing on (poly)phenol-gut microbiota interactions and the effects on human health. Annu. Rev. Food Sci. Technol. 2019, 10, 221-238. [CrossRef] [PubMed]

(C) 2019 by the authors. Licensee MDPI, Basel, Switzerland. This article is an open access article distributed under the terms and conditions of the Creative Commons Attribution (CC BY) license (http://creativecommons.org/licenses/by/4.0/). 